\title{
A Rotundabaloghiidae KonTSCHÁn, 2010 (Acari, Mesostigmata) család fajainak új, illusztrált katalógusa
}

\author{
KONTSCHÁN JENŐ \\ Magyar Tudományos Akadémia, Agrártudományi Kutatóközpont, \\ Növényvédelmi Intézet, Állattani Osztály, 1525 Budapest, Pf. 102. \\ E-mail: kontschan.jeno@agrar.mta.hu
}

Összefoglalás. Jelen dolgozatban összesítem az eddig ismert valamennyi, a Rotundabalogiidae családba tartozó atka faj összes irodalmi adatát, legfontosabb karaktereiket illusztrálom, a magasabb rendszertani kategóriákat (család, alcsalád, nem, alnem) bemutatom, illetve ezekhez határozókulcsot adok.

Kulcsszavak: Korongatka, taxonómia, faunisztika, határozó, trópus.

\section{Bevezetés}

A Rotundabaloghiidae KONTSCHÁN, 2010 egyike a legfajgazdagabb korongatka családoknak a trópusi területeken (WIŚNIEWSKI 1993), ahol talajban, avarban, mohában fordulnak elö, leggyakrabban természetes élőhelyeken, bár a család tagjait találták már agrárterületeken is (KONTSCHÁN 2016). Jelenleg több mint száz faja ismert (WIŚNIEWSKI \& HIRSCHMANN 1993, KONTSCHÁN 2004, 2005, 2006, 2007a, 2007b, 2007c, 2008a, 2008b, 2008c, 2009a, 2009b, 2009c, 2009d), és ez az egyetlen családja az Uropodina (korongatka) alrendnek, ahol kladisztikai vizsgálat alapján erősítették meg a család és a családba tartozó nemek és alnemek rokonsági kapcsolatait (KONTSCHÁN 2010a).

A családot eredetileg Rotundabaloghia HIRSCHMANN, 1975 nemként HIRSCHMANN (1975a) írta le BALOGH JÁNOS professzor új-guineai gyüjtései alapján. WERNER HIRSCHMANN, a korongatkák kiemelkedő kutatója BALOGH JÁNOS új-guineai anyagát áttanulmányozva apró (300-500 $\mu \mathrm{m}$ hosszú) és kerekded korongatkákra figyelt fel. A jellegzetes kerek testalak és BALOGH JÁNOS neve alapján alkotta meg a génusz nevét: Rotundabaloghia.

WERNER HIRSCHMANN haláláig kollégáival több mint 120 Rotundabaloghia fajt fedezett fel és írt le a világ minden tájáról. HIRSCHMANN (1961) speciális rendszerében a Rotundabaloghia mint „Ganggattung” szerepelt, azonban ez a rendszer számos kritikát kapott, mert nem felelt meg a Zoológiai Nevezéktan Nemzetközi Kódexe (ICZN) ajánlásainak, ezért később HIRSCHMANN (1979) revideálta elképzeléseit. Ebben az új rendszerben említi először családként a taxont (Rotundabaloghidae HIRSCHMANN, 1979) két külön génusszal. A két nemet a nőstények ivarlemezének alakja alapján választotta szét: a három- 
szögletes ivarlemezü Angulobaloghia HIRSCHMANN, 1979 és a pajzs vagy nyelv alakú ivarlemezü Rotundabaloghia HIRSCHMANN, 1975. Sajnos később HIRSCHMANN (1993) visszatért korábbi elképzeléseihez és összefoglaló munkáiban újra csak nemként említette a Rotundabaloghia taxont (HIRSCHMANN 1993, HIRSCHMANN \& WIŚNIEWSKI 1993, WIŚNIEWSKI 1993), valamint 11 fajcsoportja osztotta azt a hasi karakterei alapján (HIRSCHMANN 1992b). A taxont illetőleg az egyes zoogeográfiai régiók feltártsága eltér egymástól: Ausztrália és az orientális régiók kevéssé ismertek. HIRSCHMANN (1975a) ÚjGuineaból írta le a nemet, néhány tudományra új faj felfedezésével. Még ebben az évben HIRSCHMANN \& HIRAMATSU (1975) Japánból, Új-Guineából, a Fülöp-szigetekről és Indonéziából közölt új fajokat. HIRAMATSU (1983) számos új fajt fedezett fel és írt le Borneóról (Indonézia) is. A nem első afrikai adatát a trópusi Ruandából és Kamerunból közölte HIRSCHMANN (1984), majd Ghánában, a Kongói Köztársaságban és Tanzániában is megtalálta képviselőit (HIRSCHMANN (1992a). A Neotrópusi regió a legjobban ismert területe a Rotundabaloghia nem előfordulásainak. HIRSCHMANN (1972) már korábban leírt addig ismeretlen kinézetü korongatkákat és akkor az Uroobovella BERLESE, 1903 nembe helyezte el öket, mint U. guttasetta HIRSCHMANN, 1972 és U. unguiseta HIRSCHMANN, 1972. Egy évvel később (HIRSCHMANN 1973) Brazília területéről egy újabb hasonló fajt írt le Uroobovella rotunda HIRSCHMANN, 1973 néven. Később ezt a három fajt már átsorolta a Rotundabaloghia nembe (HIRSCHMANN 1981, 1984). HIRSCHMANN az 1990-es évek elején intenzíven vizsgálta a Rotundabaloghia nem további neotrópusi előfordulásait és leírt 28 fajt Kolumbiából (HIRSCHMANN 1992b), és további 41 fajt Brazíliából, Ecuadorból, Peruból, Venezuelából és Guatemalából.

Később KONTSCHÁN (2010a) újra család szintre emelte a nemet, alcsaládokat, nemeket és alnemeket különített el, szinonimizált több mint 10 nevet, illetve leírt több új fajt. Ezeket az eredményeket egy önálló monográfiában foglalta össze (KONTSCHÁN 2010a). Az az óta eltelt pár évben számos újonnan felfedezett fajjal egészült ki ezen érdekes taxon ismerete, ezért szükségesnek tünt egy új illusztrált katalógus összeállítása.

\section{Anyag és módszer}

Jelen dolgozat az eddigi összes irodalmi említés alapján készült, az összes korábban említett nevet és elterjedési adatot tartalmazza. A katalógus alapja KONTSCHÁN (2010a) dolgozata, amely az újabb irodalmi adatokkal egészítettem ki. A Rotundabaloghia (Circobaloghia) alnem esetében, a könnyebb kezelhetőség miatt zoogeoráfiai egységenként tárgyalom a fajokat. Minden fajról eredeti, Leica DM 1000 rajzolófeltétes mikroszkóppal készült illusztrációt adok, amely a legfontosabb azonosító karaktereket mutatja. 


\section{Eredmények}

\section{Rotundabaloghiidae KONTSCHÁN, 2010 család}

Rotundabaloghidae (sic!) HIRSCHMAN 1979: 69.

Rotundabaloghiidae HIRSCHMAN 1979: KONTSCHÁN 2010a.

Rotundabaloghiidae KONTSCHÁN, 2010a: HALLIDAY 2016.

Diagnózis: Kis termetủ atkák, a test hossza 250-500 $\mu \mathrm{m}$. Dorzális idiosoma konvex. Dorzális lemez teljesen összenőtt a marginális lemezzel. A ventrális szőrök redukálódtak.

Elterjedés: Circum-trópikus.

Típus nem: Rotundabaloghia HiRSCHMANN, 1975.

Megjegyzés: HALLIDAY (2016) megállapította, hogy HIRSCHMANN (1979) a családok leírásánál sem leírást nem adott, sem típus génuszt nem jelölt ki, így ezek a családnevek érvénytelenek (nomina nuda). Azonban KONTSCHÁN (2010a) munkájában felállította a Rotundabaloghiinae alcsaládot és diagnózist is adott, ezért ez a név érvényes. Azonban nem csak alcsaládszinten, hanem családszintre emelve is, de nem Rotundabaloghiidae HIRSCHMANN, 1979, hanem Rotundabaloghiidae KONTSCHÁN, 2010 néven.

\section{Rotundabaloghiinae KONTSCHÁN, 2010 alcsalád}

Rotundabaloghiinae KONTSCHÁN, 2010a: p. 21.

Diagnózis: A nőstény ivari lemezének az alsó szegélye túlnyúlik a 4. láb csípőinek hátulsó szegélyén. A hím ivarnyílása a 4. láb csípői között található.

Elterjedés: Circum-trópikus.

Típus nem: Rotundabaloghia HiRSCHMANN, 1975.

Az alcsalád nemei: Angulobaloghia HIRSCHMANN, 1979 és Rotundabaloghia HIRSCHMANN, 1979.

\section{Angulobaloghia HiRSCHMANN, 1979 nem}

Angulobaloghia HIRSCHMANN 1979: p. 61.

Angulobaloghia KONTSCHÁN 2010a: p. 22.

Diagnózis: Dorzális szőrök egyforma méretűek és alakúak. A nőstény ivarlemeze háromszögletes, négyzet vagy félkör alakú. Peritréma gomba vagy kampó alakú.

Típus faj: Angulobaloghia angulogynella (HIRSCHMANN, 1975).

Elterjedés: Új-Guinea, Indonézia, Malajzia, Fülöp-szigetek, Vietnam, Japán, Kína (Hong Kong), India. 
Angulobaloghia angulogynella (HIRSCHMANN, 1975) (1. ábra)

Rotundabaloghia angulogynella HIRSCHMANN: 1975c p. 26, Fig. 26.

Rotundabaloghia angulogynella: HIRSCHMANN, 1975c p. 30, HIRAMATSU \& HIRSCHMANN 1992 p. 9, WIŚNIEWSKI \& HIRSCHMANN 1993 p. 69, WIŚNIEWSKI 1993a p. 281, WIŚNIEWSKI 1993b p. 394, KONTSCHÁN 2010a p. 22.

Elterjedés: Új-Guinea.

\section{Angulobaloghia angustigynella (HIRSCHMANN, 1975) (2. ábra)}

Rotundabaloghia angustigynella HIRSCHMANN: 1975c p. 26, Fig. 27.

Rotundabaloghia angustigynella: HIRSCHMANN, 1975c p. 31, HIRAMATSU \& HIRSCHMANN 1992 p. 9, WIŚNIEWSKI \& HIRSCHMANN 1993 p. 69, WIŚNIEWSKI 1993a p. 282, WIŚNIEWSKI 1993b p. 394, KONTSCHÁN 2010a p. 22.

Elterjedés: Új-Guinea.

\section{Angulobaloghia aoki (HIRAMATSU, 1979) (16. ábra)}

Rotundabaloghia aoki HIRAMATSU: 1979 pp. 87-88, Fig. 77.

Rotundabaloghia aoki: WIŚNIEWSKI \& HIRSCHMANN 1993 p. 74, WIŚNIEWSKI 1993a p. 273, WIŚNIEWSKI 1993b p. 394.

Angulobaloghia aoki: KONTSCHÁN 2010a p. 24.

Elterjedés: Japán.

\section{Angulobaloghia cuyi (HIRAMATSU \& HirschMAnN, 1992) (5. ábra)}

Rotundabaloghia cuyi HiRAMATSU \& HiRSCHMANN: 1992 pp. 9 és 26, Figs pp. 18-19.

Rotundabaloghia cuyi: HIRAMATSU \& HIRSCHMANN 1992 pp. 17-19, WIŚNIEWSKI \& HIRSCHMANN 1993 p. 69, WIŚNIEWSKI 1993a p. 280, WIŚNIEWSKI 1993b p. 395, KONTSCHÁN 2010a p. 23.

Elterjedés: Fülöp-szigetek.

\section{Angulobaloghia danyii (KONTSCHÁN, 2008) (9. ábra)}

Rotundabaloghia danyii KONTSCHÁN: 2008c pp. 21-23, Figs 25-26.

Angulobaloghia danyii: KONTSCHÁN 2010a p. 23.

Elterjedés: Indonézia, Borneó.

\section{Angulobaloghia indica KONTSCHÁN, 2011 (11. ábra)}

Angulobaloghia indica KONTSCHÁN: 2011 p. 122, Figs 5-6.

Elterjedés: India. 


\section{Angulobaloghia latigynella (HIRSCHMANN, 1975) (3. ábra)}

Rotundabaloghia latigynella HIRSCHMANN: 1975b p. 26, Fig. 28.

Rotundabaloghia latigynella: HIRSCHMANN, 1975c p. 31, HIRAMATSU \& HIRSCHMANN 1992 p. 10, WIŚNIEWSKI \& HIRSCHMANN 1993 p. 70, WIŚNIEWSKI 1993a p. 282, WIŚNIEWSKI 1993b p. 395, KONTSCHÁN 2010a p. 22.

Elterjedés: Új-Guinea.

\section{Angulobaloghia luzonensis (HIRAMATSU \& HIRSCHMANN, 1992) (4. ábra)}

Rotundabaloghia luzonensis HiRAMATsu \& HirSCHMANN: 1992 p. 10, Figs p. 20.

Rotundabaloghia angulogynella: HIRAMATSU \& HIRSCHMANN 1992 pp. 19-21. WiśNIEWSKI \& HIRSCHMANN 1993 p. 70, WIŚNIEWSKI 1993a p. 280, WIŚNIEWSKI 1993b p. 395.

Angulobaloghia luzonensis: KONTSCHÁN 2010a p. 23.

Elterjedés: Fülöp-szigetek.

\section{BorneóAngulobaloghia pedunculata KONTSCHÁN \& KISS, 2015 (14. ábra)}

Angulobaloghia pedunculata KONTSCHÁN \& KISS: 2015 pp. 516-518, Figs 1-11.

Elterjedés: Indonézia, Szumátra.

\section{Angulobaloghia pyrigynella (HIRSCHMANN, 1992) (6. ábra)}

Rotundabaloghia sp. B1.: HIRAMATSU 1983 p. 132-133, Figs 54-59.

Rotundabaloghia pyrigynella HIRSCHMANN: 1992 p. 10.

Rotundabaloghia pyrigynella: WIŚNIEWSKI \& HIRSCHMANN 1993 p. 70, WIŚNIEWSKI 1993a p. 278, WIŚNIEWSKI 1993b p. 396.

Angulobaloghia pyrigynella: KONTSCHÁN 2010a p. 23.

Elterjedés: Indonézia, Borneó.

\section{Angulobaloghia rutra KONTSCHÁN, 2014 (12. ábra)}

Angulobaloghia rutra KONTSCHÁN: 2014 pp. 36-39, Figs 1-10.

Elterjedés: Sabah, Malajzia.

Angulobaloghia scrobia KONTSCHÁN \& STARỳ, 2011 (15. ábra)

Angulobaloghia scrobia KONTSCHÁN \& STARỳ: 2011 p. 22, Figs 58-60.

Elterjedés: Vietnam.

\section{Angulobaloghia staryi KONTSCHÁN, 2015 (13. ábra)}

Angulobaloghia staryi KonTSCHÁN: 2015a pp. 45-48, Figs 1-11.

Elterjedés: Hong Kong (Kína). 

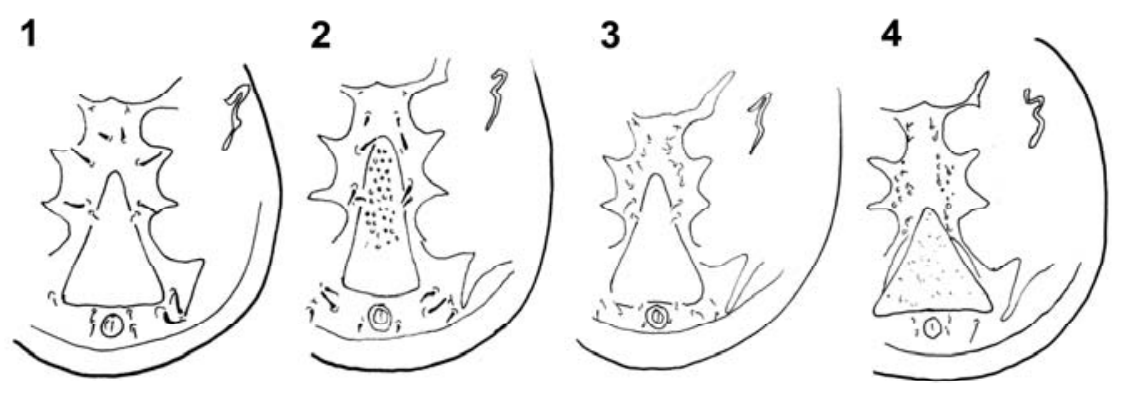

5
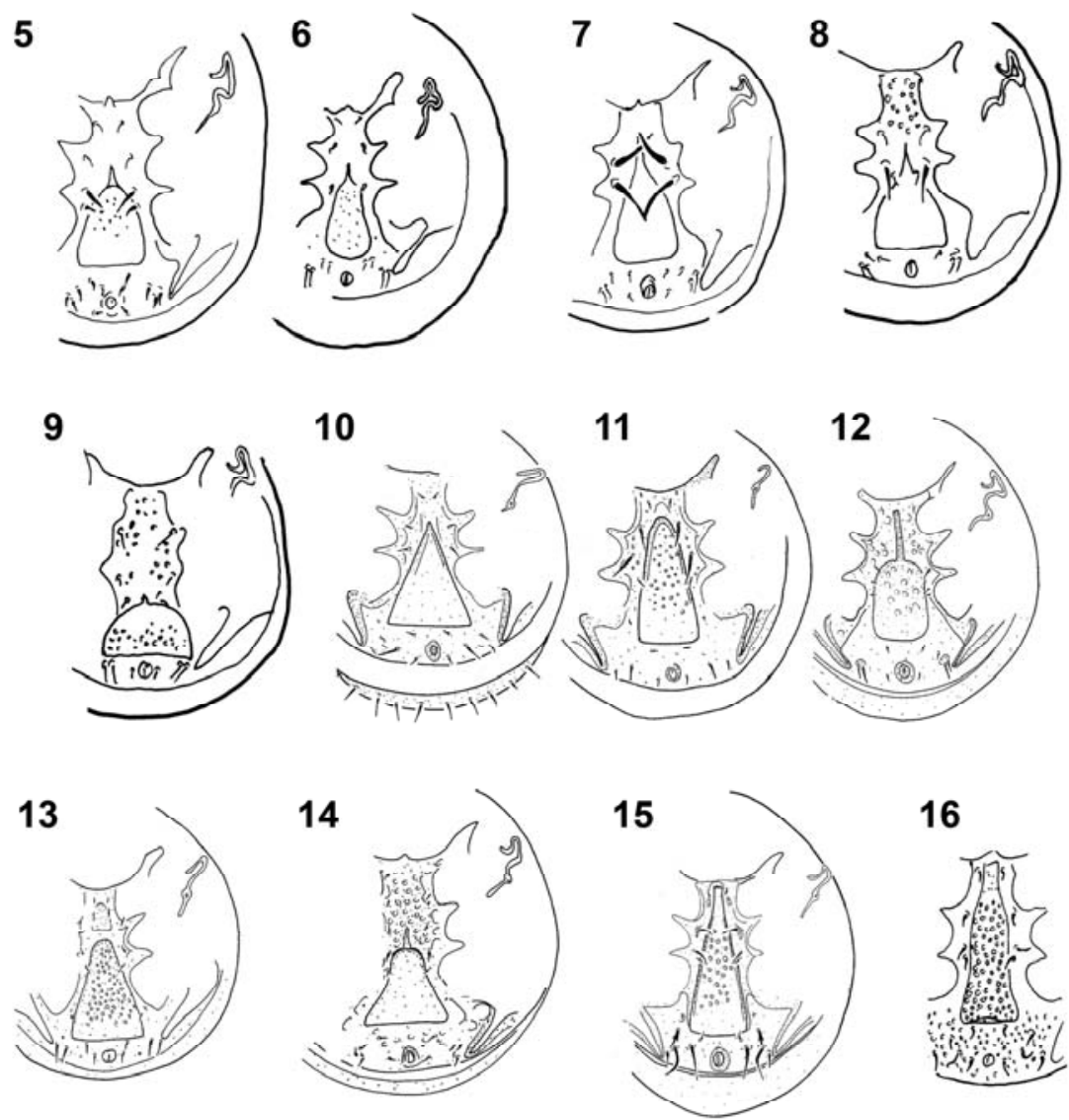

16

1-16. ábrák. Az Angulobaloghia fajok hasi nézete a legfontosabb karakterekkel. Figures 1-16. Ventral aspect of the known Angulobaloghia species. 
Angulobaloghia tamilica KoNTSCHÁN, 2011 (10. ábra)

Angulobaloghia tamilica KONTSCHÁN: 2011 pp. 121-122, Figs 1-4.

Elterjedés: India.

Angulobaloghia triangulata (KONTSCHÁN, 2008) (7. ábra)

Rotundabaloghia triangulata KONTSCHÁN: 2008c pp. 19-20, Figs 12-15.

Elterjedés: Vietnam.

Angulobaloghia vietnamensis (KONTSCHÁN, 2008) (8. ábra)

Rotundabaloghia vietnamensis KONTSCHÁN: 2008c pp. 20-21, Figs 16-20.

Elterjedés: Vietnam.

\section{Rotundabaloghia HIRSCHMANN, 1975 nem}

Rotundabaloghia HIRSCHMANN 1975: p. 23.

Rotundabaloghia KONTSCHÁN 2010a: p. 26.

Diagnózis: A háti szőrök egyforma méretủek és alakúak, vagy a j sorban néhány rövidebb ször található. A nőstény ivarlemeze nyelv vagy pajzs alakú. A peritréma kampós.

Típus faj: R. baloghi HIRSCHMANN, 1975.

Elterjedés: Circum-trópusi.

\section{Rotundabaloghia HiRSCHMANN, 1975 alnem}

Rotundabaloghia KONTSCHÁN, 2010a: p. 27.

Diagnózis: A háti szőrök méretben és alakban nem egységesek: Három vagy négy pár rövid, tủ alakú szört találunk a j sorban, a többi ször hosszú, és vagy pillás vagy sima szegélyü. Az St1, St2 és St3 szőrök hosszúak, St4 nagyon rövid. A nőstény ivarlemeze nyelv alakú, és apró tüske alakú elülső függeléket visel. A peritréma kampós.

Típus faj: R. baloghi HIRSCHMANN, 1975.

Elterjedés: Új-Guinea, Fülöp-szigetek, Japán, Tajvan, Indonézia és Hong Kong.

\section{Rotundabaloghia (Rotundabaloghia) baloghi HIRSCHMANN, 1975 (17. ábra)}

Rotundabaloghia baloghi HIRSCHMANN: 1975c p. 28, Fig. 24.

Rotundabaloghia baloghi: HIRSCHMANN, 1975c p. 28 és 29, WIŚNIEWSKI \& HIRSCHMANN 1993 p. 70, WIŚNIEWSKI 1993a p. 282, WIŚNIEWSKI 1993b p. 394, KONTSCHÁN 2008a pp. 16-17, Figs 1-4 és 8-9, KONTSCHÁN 2010a p. 27.

Rotundabaloghia baloghioides HIRSCHMANN, 1975 (syn: KONTSCHÁN 2010a)

Rotundabaloghia baloghioides HIRSCHMANN: 1975c p. 28, Fig. 35.

Rotundabaloghia baloghioides: HIRSCHMANN 1975c p. 28 és 34, WIŚNIEWSKI \& HIRSCHMANN 1993 p. 70, WIŚNIEWSKI 1993a p. 282, WIŚNIEWSKI 1993b p. 394.

Rotundabaloghia baloghisimilis HIRSCHMANN, 1975 (syn: KONTSCHÁN 2010a) 
Rotundabaloghia baloghisimilis HIRSCHMANN: 1975c p. 28, Fig. 36.

Rotundabaloghia baloghisimilis: HIRSCHMANN 1975c p. 28 és 34, WIŚNIEWSKI \& HIRSCHMANN 1993 p. 70, WIŚNIEWSKI 1993a p. 282, WIŚNIEWSKI 1993b p. 394.

Rotundabaloghia latibaloghia HIRSCHMANN, 1975 (syn: KONTSCHÁN 2010a)

Rotundabaloghia latibaloghia HIRSCHMANN: 1975b p. 27, Fig. 37.

Rotundabaloghia latibaloghia: HIRSCHMANN 1975c p. 28 és 334, WIŚNIEWSKI \& HIRSCHMANN 1993 p. 70-71, WIŚNIEWSKI 1993a p. 282, WIŚNIEWSKI 1993b p. 395.

Elterjedés: Új-Guinea.

\section{Rotundabaloghia (Rotundabaloghia) macroseta HIRSCHMANN, 1975 (18. ábra)}

Rotundabaloghia macroseta HIRSCHMANN: 1975c p. 27, Fig. 34.

Rotundabaloghia macroseta: HIRSCHMANN, 1975c p. 28 és 33, WIŚNIEWSKI \& HIRSCHMANN 1993 pp. 77, WIŚNIEWSKI 1993a p. 282, WIŚNIEWSKI 1993b p. 395, KONTSCHÁN 2010a p. 28.

Elterjedés: Új-Guinea.

\section{Rotundabaloghia (Rotundabaloghia) mahunkai HIRSCHMANN, 1975 (19. ábra)}

Rotundabaloghia mahunkai HIRSCHMANN: 1975c p. 27, Fig. 33.

Rotundabaloghia mahunkai: HIRSCHMANN 1975c p. 28 és 33, WIŚNIEWSKI \& HIRSCHMANN 1993 p. 77, WIŚNIEWSKI 1993a p. 282, WIŚNIEWSKI 1993b p. 395, KONTSCHÁN 2008a pp. 18-19, Figs 1-4 és 10-11, KONTSCHÁN 2010a p. 28.

Elterjedés: Új-Guinea.

\section{Rotundabaloghia (Rotundabaloghia) monomacroseta HIRSCHMANN, 1975 (20. ábra)}

Rotundabaloghia monomacroseta HIRSCHMANN: 1975c p. 27, Fig. 30.

Rotundabaloghia monomacroseta: HIRSCHMANN 1975c p. 28 és 32, WIŚNIEWSKI \& HIRSCHMANN 1993 p. 76, WIŚNIEWSKI 1993a p. 282, WIŚNIEWSKI 1993b p. 396, KONTSCHÁN 2010a p. 28.

Elterjedés: Új-Guinea.

\section{Rotundabaloghia (Rotundabaloghia) kaszabi HIRSCHMANN, 1975 (21. ábra)}

Rotundabaloghia kaszabi HIRSCHMANN: 1975bc p. 27, Fig. 29.

Rotundabaloghia kaszabi: HIRSCHMANN 1975c p. 28 és 33, WIŚNIEWSKI \& HIRSCHMANN 1993 p. 75, WIŚNIEWSKI 1993a p. 282, WIŚNIEWSKI 1993b p. 395, KONTSCHÁN 2010a pp. 28-29.

Elterjedés: Új-Guinea. 
Rotundabaloghia (Rotundabaloghia) kaszabisimilis HIRSCHMANN, 1975 (22. ábra)

Rotundabaloghia kaszabisimilis HIRSCHMANN: 1975c p. 27, Fig. 32.

Rotundabaloghia kaszabisimilis: 1975c p. 28 és 33, WIŚNIEWSKI \& HIRSCHMANN 1993 p. 76, WIŚNIEWSKI 1993a p. 282, WIŚNIEWSKI 1993b p. 395, KONTSCHÁN 2010a p. 29.

Elterjedés: Új-Guinea.

\section{Rotundabaloghia (Rotundabaloghia) pilosa HiRsCHMANn, 1975 (23. ábra)}

Rotundabaloghia pilosa HIRSCHMANN: 1975c p. 27, Fig. 23.

Rotundabaloghia pilosa: HIRSCHMANN 1975c p. 28 és 29, WIŚNIEWSKI \& HIRSCHMANN 1993 p. 76, WiŚNIEWSKI 1993a p. 282, WIŚNIEWSKI 1993b p. 396, KONTSCHÁN 2010a p. 29.

Elterjedés: Új-Guinea.

\section{Rotundabaloghia (Rotundabaloghia) hirschmanni HIRAMATSU, 1977 (24. ábra)}

Rotundabaloghia hirschmanni HIRAMATSU: 1977 pp. 19-20, Fig. 6.

Rotundabaloghia hirschmanni: WIŚNIEWSKI \& HIRSCHMANN 1993 p. 75, WIŚNIEWSKI 1993a p. 273, WIŚNIEWSKI 1993b p. 395, KONTSCHÁN 2010a p. 29.

Elterjedés: Japán.

Rotundabaloghia (Rotundabaloghia) korsosi KonTSCHÁN, 2008 (25. ábra)

Rotundabaloghia korsosi KonTSCHÁn: 2008b pp. 45-50, Figs 1-14, KONTSCHÁN 2010a p. 29.

Elterjedés: Tajvan.

Rotundabaloghia (Rotundabaloghia) makilingensis HiRAMATSU \& HirsCHMANN, 1992 (26. ábra)

Rotundabaloghia makilingensis HIRAMATSU \& HIRSCHMANN: 1992 pp. 22-25, Fig. p. 24.

Rotundabaloghia makilingensis: WIŚNIEWSKI \& HIRSCHMANN 1993 p. 75, WIŚNIEWSKI 1993a p. 280, WIŚNIEWSKI 1993b p. 396, KONTSCHÁN 2010a p. 30.

Elterjedés: Fülöp-szigetek.

\section{Rotundabaloghia (Rotundabaloghia) makilingoides HIRSCHMANN, 1992 (27. ábra)}

Rotundabaloghia makilingoides HIRSCHMANN: 1992 p. 25, Fig. p.25.

Rotundabaloghia makilingoides: WIŚNIEWSKI \& HIRSCHMANN 1993 p. 75, WIŚNIEWSKI 1993a p. 280, WIŚNIEWSKI 1993b p. 396, KONTSCHÁN 2010a: p. 30.

Elterjedés: Fülöp-szigetek. 

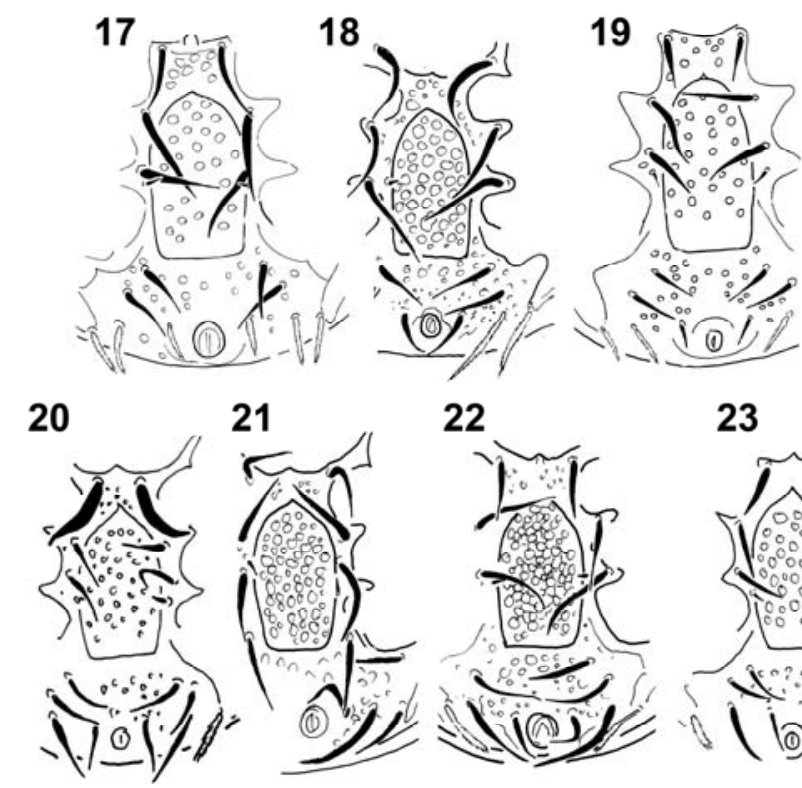

21

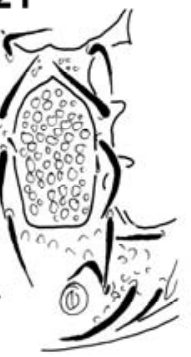

22

23

24

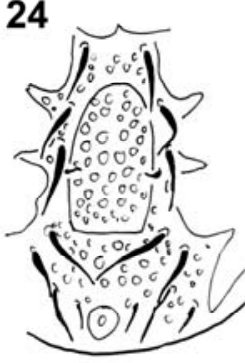

25

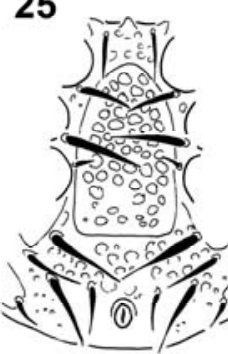

26
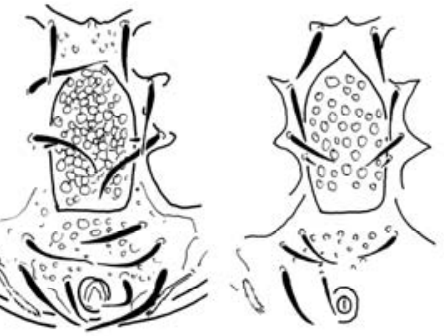

28

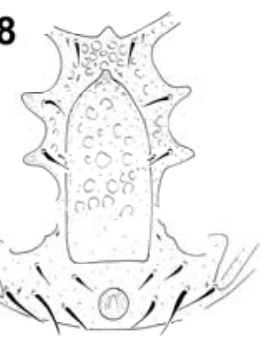

29

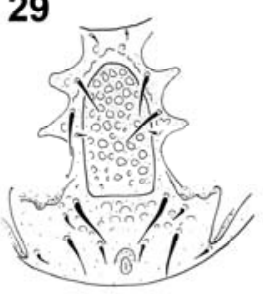

17-29. ábrák. A Rotundabaloghia (Rotundabaloghia) fajok hasi nézete a legfontosabb karakterekkel.

Figures 17-29. Ventral aspect of the known Rotundabaloghia (Rotundabaloghia) species. 
Rotundabaloghia (Rotundabaloghia) wangi KONTSCHÁN \& KISS, 2015 (28. ábra)

Rotundabaloghia (Rotundabaloghia) wangi KONTSCHÁN \& KISs: 2015 pp. 518-520, Figs 12-24.

Elterjedés: Indonézia, Szumátra.

\section{Rotundabaloghia (Rotundabaloghia) hongkongensis KONTSCHÁN, 2015 (29. ábra)}

Rotundabaloghia (Rotundabaloghia) hongkongensis KONTSCHÁN: 2015a pp. 48-50, Figs 12-20.

Elterjedés: Hong Kong (Kína).

\section{Circobaloghia KONTSCHÁN, 2010 alnem}

Circobaloghia KONTSCHÁN 2010a: p. 33.

Diagnózis: Az összes dorzális szőr egyforma méretủ és alakú. A nőstény ivarlemeze nyelv vagy pajzs alakú. A peritréma kampós vagy R-alakú.

Típus faj: Rotundabaloghia (Circobaloghia) ecuadorensis (HIRSCHMANN, 1992)

Elterjedés: Cirkumtrópikus.

Megjegyzés: A Rotundabaloghia (Circobaloghia) alnem fajai között széles elterjedésü, több kontinensen előforduló fajt eddig még nem találtam, ezért a nagy fajszám miatt az alnem tagjait földrajzi-, zoogeográfiai egységenként tárgyalom.

\section{Afrotrópikus régió Rotundabaloghia (Circobaloghia) fajai}

Az afrotrópikus Rotundabaloghia (Circobaloghia) fajokat három elkülönült csoportban tárgyalom: A felosztás WALLACE (1876) munkáján alapul, amelyet WiŚNIEWSKI (1993a) is használt, és újabban KREFT \& JETZ (2010) is megerősített. Az elkülönítésben a klímatikus viszonyoknak van elsődleges szerepe, a nyugat-afrikai szubrégió [Ethipian west in WIŚNIEWSKI (1993a: 291.)] nedvesebb klímájú, esőerdőkkel borított régió (ide tartozik nyugat-afrikai partvidéken: Ghána és Elefántcsontpart, illetve a Kongó-medencében Kamerun és a Kongói-köztársaság). Ellenben a kelet-afrikai szubrégió [Ethiopian east in WIŚNIEWSKI (1993a: 291)] szárazabb szavannákkal és tengerparti erdőkkel rendelkezik. A Malgas szubrégiót faunájának speciális, izolált fejlődése miatt tárgyalom külön. Eddigi vizsgálataim során nem találtam olyan korongatka fajt, amely több afrotrópikus szubrégióban is előfordulna.

\section{Nyugat-afrikai szubrégió Rotundabaloghia (Circobaloghia) fajai}

\section{Rotundabaloghia (Circobaloghia) africaguttaseta HIRSCHMANN, 1984 (30. ábra)}

Rotundabaloghia africaguttaseta HIRSCHMANN: 1984 p. 30, Fig. p. 30.

Rotundabaloghia africaguttaseta: HIRSCHMANN 1992a p. 26, HIRSCHMANN 1992d p. 97, WIŚNIEWSKI \& HIRSCHMANN 1993 p. 78, WIŚNIEWSKI 1993a p. 243, WIŚNIEWSKI 1993 b p. 394, KONTSCHÁN 2010a p. 33. 
Elterjedés: Kamerun.

Rotundabaloghia (Circobaloghia) bueaensis HIRSCHMANN, 1992 (38. ábra)

Rotundabaloghia bueaensis HIRSCHMANN: 1992a p. 43, Fig. p. 44.

Rotundabaloghia bueaensis: HIRSCHMANN 1992b d. 98, WIŚNIEWSKI \& HIRSCHMANN 1993 p. 77, WIŚNIEWSKI 1993a p. 243, WiśNIEWSKI 1993b p. 394, KONTSCHÁN 2010a p. 33 .

Elterjedés: Kamerun.

\section{Rotundabaloghia (Circobaloghia) camerunis HIRSCHMANN, 1984 (39. ábra)}

Rotundabaloghia camerunis HIRSCHMANN: 1984 p. 31, Fig. p. 31.

Rotundabaloghia camerunis: HIRSCHMANN 1992d p. 26, HIRSCHMANN 1992b p. 97, WIŚNIEWSKI \& HIRSCHMANN 1993 p. 79, WIŚNIEWSKI 1993a p. 243, WIŚNIEWSKI 1993 b p. 394, KONTSCHÁN 2010a p. 33.

Elterjedés: Kamerun.

\section{Rotundabaloghia (Circobaloghia) campanellae HIRSCHMANN, 1992 (31. ábra)}

Rotundabaloghia campanellae HIRSCHMANN: 1992a p. 41, Fig. p. 42.

Rotundabaloghia campanellae: HIRSCHMANN 1992d p. 98, WiśNIEWSKI \& HIRSCHMANN 1993 p. 76, WIŚNIEWSKI 1993a p. 243, WIŚNIEWSKI 1993b p. 394, KONTSCHÁN 2010a p. 34.

Elterjedés: Kamerun.

Rotundabaloghia (Circobaloghia) campanellasimilis HIRSCHMANN, 1992 (40. ábra)

Rotundabaloghia campanellasimilis HIRSCHMANN: 1992a p. 41, Fig. p. 43.

Rotundabaloghia campanellasimilis: HIRSCHMANN 1992d p. 97, WIŚNIEWSKI \& HIRSCHMANN 1993 p. 75, WIŚNIEWSKI 1993a p. 243, WIŚNIEWSKI 1993b p. 394, KONTSCHÁN 2010a p. 34.

Elterjedés: Kamerun.

\section{Rotundabaloghia (Circobaloghia) masoumbouensis HIRSCHMANN, 1992 (32. ábra)}

Rotundabaloghia masoumbouensis HIRSCHMANN: 1992a p. 31, Fig. p. 34.

Rotundabaloghia masoumbouensis: HIRSCHMANN 1992d p. 97, WIŚNIEWSKI \& HIRSCHMANN 1993 p. 73, WIŚNIEWSKI 1993a p. 244, WIŚNIEWSKI 1993b p. 396, KONTSCHÁN 2010a p. 34.

Elterjedés: Kamerun. 


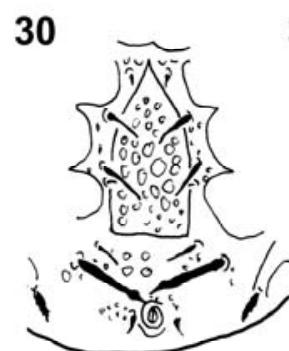

31

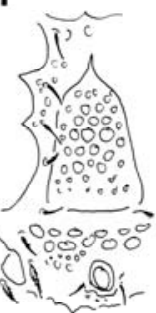

32

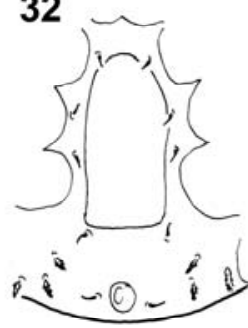

33
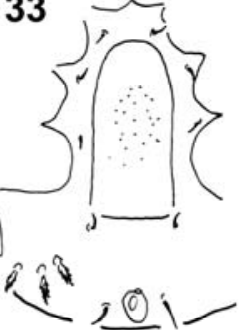

34

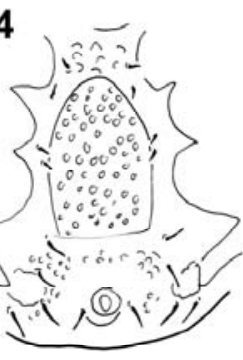

35

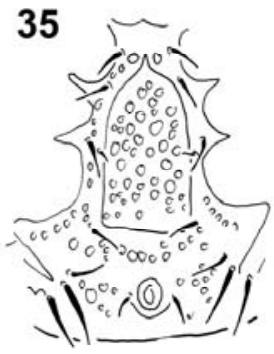

36

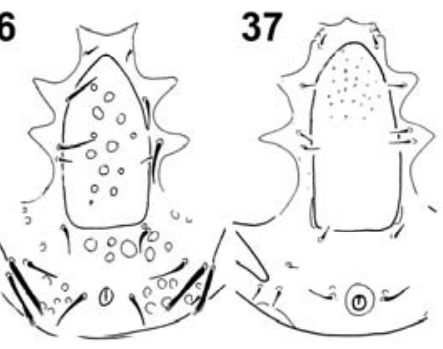

38

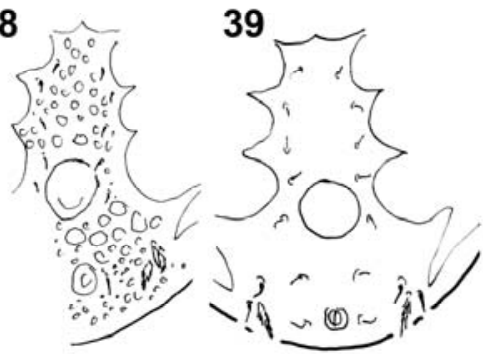

42

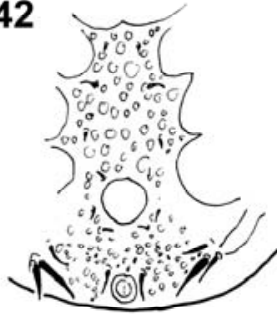

40

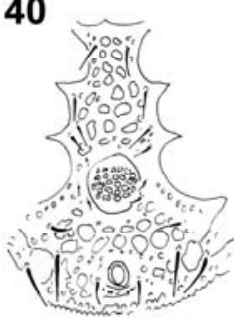

43

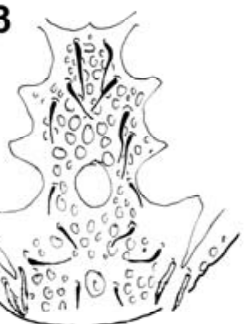

30-43. ábra. A nyugat-afrikai Rotundabaloghia (Circobaloghia) fajok hasi nézete a legfontosabb karakterekkel.

Figures 30-43. Ventral aspect of the known West-African Rotundabaloghia (Circobaloghia) species. 
Rotundabaloghia (Circobaloghia) masoumbouoides HIRSCHMANN, 1992 (33. ábra)

Rotundabaloghia masoumbouoides HIRSCHMANN: 1992a p. 35, Fig. p. 34.

Rotundabaloghia masoumbouoides: HIRSCHMANN 1992d p. 97, WIŚNIEWSKI \& HIRSCHMANN 1993 p. 79, WIŚNIEWSKI 1993a p. 244, WIŚNIEWSKI 1993b p. 396, KONTSCHÁN 2010a p. 34.

Elterjedés: Kamerun.

\section{Rotundabaloghia (Circobaloghia) perstructura HIRSCHMANN, 1984 (41. ábra)}

Rotundabaloghia perstructura HIRSCHMANN: 1984 pp. 29-30, Figs p. 30.

Rotundabaloghia perstructura: HIRSCHMANN 1992a p. 26, HIRSCHMANN 1992d p. 98, WIŚNIEWSKI \& HIRSCHMANN 1993 p. 77, WIŚNIEWSKI 1993a p. 244, WIŚNIEWSKI 1993 b p. 396, KONTSCHÁN 2010a p. 35.

Elterjedés: Kamerun.

\section{Rotundabaloghia (Circobaloghia) daelei HIRSCHMANN, 1984 (42. ábra)}

Rotundabaloghia daelei HIRSCHMANN: 1984 p. 31, Fig.

Rotundabaloghia daelei: HIRSCHMANN 1992a p. 26, HIRSCHMANN 1992d p. 98, WIŚNIEWSKI \& HIRSCHMANN 1993 p. 75, WIŚNIEWSKI 1993a p. 243, WIŚNIEWSKI 1993 b p. 395, KONTSCHÁN 2010a p. 35.

Elterjedés: Kamerun.

\section{Rotundabaloghia (Circobaloghia) congoensis HiRSCHMANN, 1992 (37. ábra)}

Rotundabaloghia congoensis HIRSCHMANN: 1992a p. 37, Fig. p. 39.

Rotundabaloghia congoensis: HIRSCHMANN 1992d p. 97, WIŚNIEWSKI \& HIRSCHMANN 1993 p. 73, WiŚNIEWSKI 1993a p. 244, WIŚNIEWSKI 1993b p. 395, KONTSCHÁN 2008 38-39, Figs 72-76, KonTSCHÁn 2010a p. 35.

Elterjedés: Kongói Köztársaság.

\section{Rotundabaloghia (Circobaloghia) endroedyi HIRSCHMANN, 1992 (34. ábra)}

Rotundabaloghia endroedyi HIRSCHMANN: 1992a p. 39 Fig. p. 40.

Rotundabaloghia endroedyi: HIRSCHMANN 1992d p. 97, WIŚNIEWSKI \& HIRSCHMANN 1993 p. 75, WIŚNIEWSKI 1993a p. 242, WIŚNIEWSKI 1993b p. 395, KONTSCHÁN 2010a p. 36 .

Elterjedés: Ghána.

\section{Rotundabaloghia (Circobaloghia) ghanaensis HIRSCHMANN, 1992 (43. ábra)}

Rotundabaloghia ghanaensis HIRSCHMANN: 1992a p. 41, Fig. p. 43.

Rotundabaloghia ghanaensis: HIRSCHMANN 1992d p. 98, WIŚNIEWSKI \& HIRSCHMANN 1993 p. 76, WIŚNIEWSKI 1993a p. 242, WIŚNIEWSKI 1993b p. 395, KONTSCHÁN 2010a p. 36 . 
Elterjedés: Ghána.

Rotundabaloghia (Circobaloghia) kintampoensis HiRSCHMANN, 1992 (35. ábra)

Rotundabaloghia kintampoensis HIRSCHMANN: 1992a p. 41, Fig. p. 42.

Rotundabaloghia kintampoensis: HIRSCHMANN 1992d p. 97, WIŚNIEWSKI \& HIRSCHMANN 1993 p. 75, WIŚNIEWSKI 1993a p. 242, WIŚNIEWSKI 1993b p. 395, KONTSCHÁN 2010a p. 36.

Elterjedés: Ghána.

Rotundabaloghia (Circobaloghia) browni KONTSCHÁN, 2009 (36. ábra)

Rotundabaloghia browni KONTSCHÁN: 2009d p. 36, Figs 1-6, KONTSCHÁN 2010a p. 36.

Elterjedés: Elefántcsontpart.

Kelet-afrikai szubrégió Rotundabaloghia (Circobaloghia) fajai

Rotundabaloghia (Circobaloghia) rwandae HiRSCHMANN, 1984 (44a. ábra)

Rotundabaloghia rwandae HIRSCHMANN: 1984 pp. 25-27, Figs p. 26.

Rotundabaloghia rwandae: HIRSCHMANN 1992a p. 26, HIRSCHMANN 1992d p. 98, WIŚNIEWSKI \& HIRSCHMANN 1993 p. 77, WIŚNIEWSKI 1993a p. 245, WIŚNIEWSKI 1993b p. 396, KONTSCHÁN 2008a pp. 20-21 és 28, KONTSCHÁN 2010a p. 40.

Elterjedés: Uganda és Ruanda.

\section{Rotundabaloghia (Circobaloghia) erinacea KONTSCHÁN, 2008 (45. ábra)}

Rotundabaloghia erinacea KONTSCHÁN: 2008a pp. 25-26, Figs 19-23.

Rotundabaloghia erinacea: KONTSCHÁN 2008a p. 29, KONTSCHÁN 2010a p. 41.

Elterjedés: Ruanda.

Rotundabaloghia (Circobaloghia) bukavuensis KONTSCHÁN, 2008 (46. ábra)

Rotundabaloghia bukavuensis KONTSCHÁN: 2008a pp. 27-28, Figs 24-29.

Rotundabaloghia bukavuensis: KONTSCHÁN 2008a p.28, KONTSCHÁN 2010a p. 41.

Elterjedés: Zaire.

Rotundabaloghia (Circobaloghia) spatulata KonTSCHÁN, 2004 (47. ábra)

Rotundabaloghia spatulata KONTSCHÁN: 2004 pp. 7-8, Figs 6-7.

Rotundabaloghia spatulata: KONTSCHÁN 2008a p. 29, KONTSCHÁN 2010a p. 41.

Elterjedés: Kenya. 
44

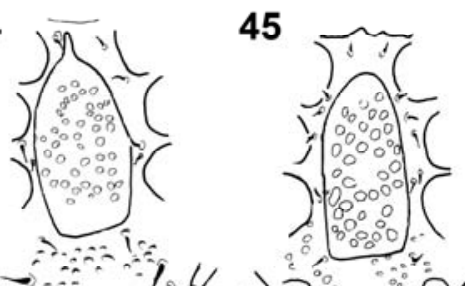

> 10,4

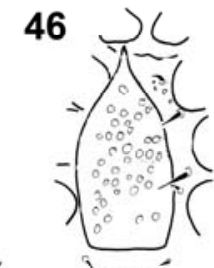

$11,0,1)$

47
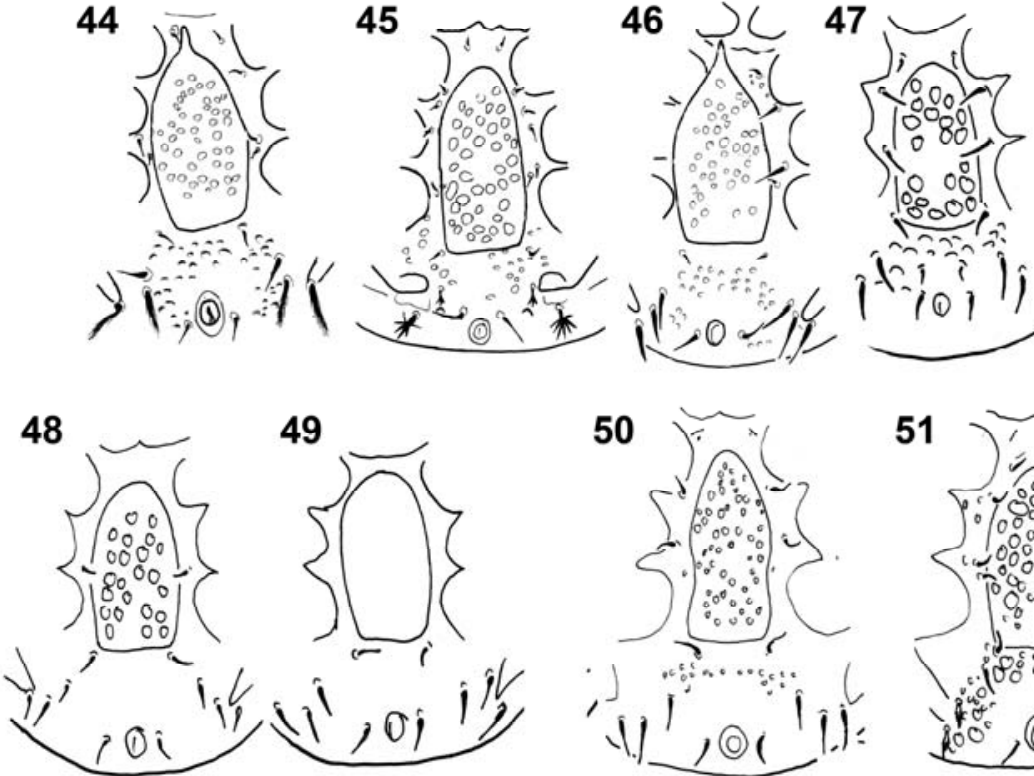

49

50
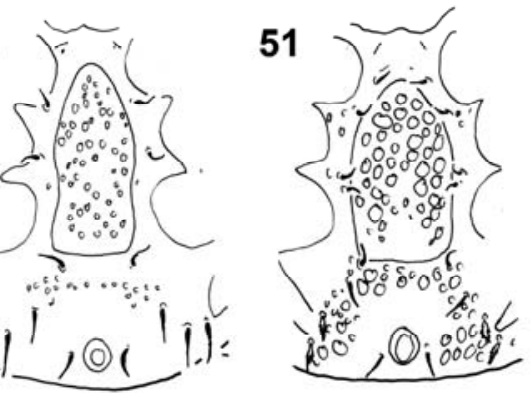

52

53

54
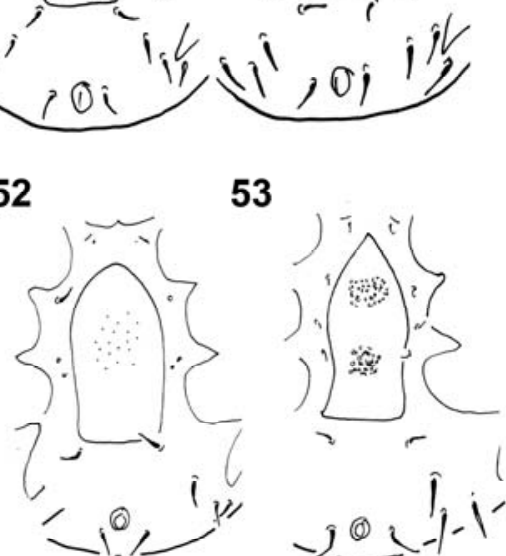

1. 1 (i)

$1-i, i j \mid \hat{i}$

56

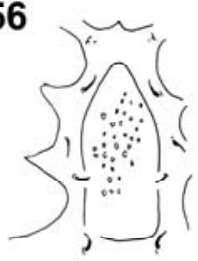

57

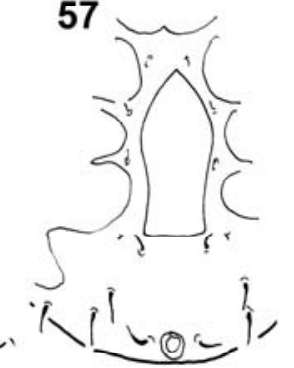

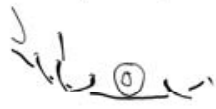

55

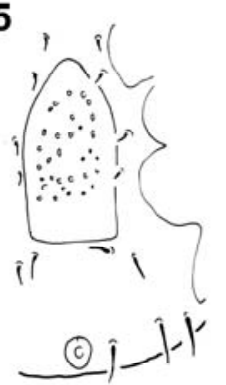

58

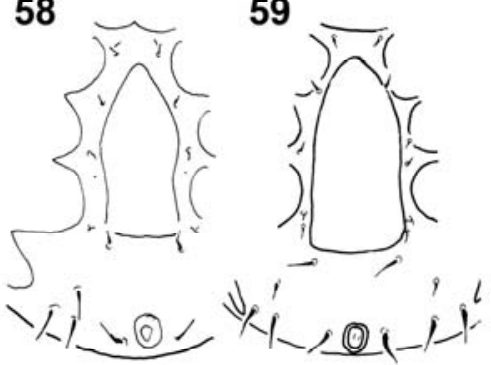

44-59. ábrák. A kelet-afrikai Rotundabaloghia (Circobaloghia) fajok hasi nézete a legfontosabb karakterekkel I.

Figures 44-59. Ventral aspect of the known East-African Rotundabaloghia (Circobaloghia) species I. 
Rotundabaloghia (Circobaloghia) heterochaeta KoNTSCHÁN, 2004 (48. ábra)

Rotundabaloghia heterochaeta KONTSCHÁN: 2004 pp. 6-7, Figs 1-5.

Rotundabaloghia heterochaeta: KONTSCHÁn 2008a p. 29, KONTSCHÁn 2010a p. 41.

Elterjedés: Kenya.

Rotundabaloghia (Circobaloghia) feherdii KONTSCHÁN, 2004 (49. ábra)

Rotundabaloghia feherdii KONTSCHÁN: 2004 pp. 8-9, Figs 8-9.

Rotundabaloghia feherdii: KONTSCHÁN 2008a p. 29, KONTSCHÁN 2009 p.741, KONTSCHÁN 2010a p. 42.

Elterjedés: Kenya.

Rotundabaloghia (Circobaloghia) lupangae HiRSCHMANN, 1992 (50. ábra)

Rotundabaloghia lupangae HIRSCHMANN: 1992a p. 35, Figs p. 36.

Rotundabaloghia lupangae: HiRSCHMANN 1992a p. 26, HIRSCHMANN 1992da p. 97, WIŚNIEWSKI \& HIRSCHMANN 1993 p. 75, WIŚNIEWSKI 1993a p. 246, WIŚNIEWSKI 1993 b p. 395, KONTSCHÁN 2008a p. 29, KONTSCHÁN 2010a p. 42.

Elterjedés: Tanzánia.

\section{Rotundabaloghia (Circobaloghia) dodomae HIRSCHMANN, 1992 (51. ábra)}

Rotundabaloghia dodomae HIRSCHMANN: 1992a pp. 37 és 39, Figs p. 38.

Rotundabaloghia dodomae: Hirschmann 1992a p. 26, HIRSCHMANN 1992d p. 98, WIŚNIEWSKI \& HIRSCHMANN 1993 p. 76, WIŚNIEWSKI 1993a p. 246, WIŚNIEWSKI 1993b p. 395, KONTSCHÁN 2008a p. 29, KONTSCHÁN 2010a p. 42.

Rotundabaloghia ukoguruensis HIRSCHMANN, 1992 (syn: KONTSCHÁN 2010a).

Rotundabaloghia ukoguruensis HIRSCHMANN: 1992a p. 43, Figs p. 44.

Rotundabaloghia ukoguruensis: HIRSCHMANN 1992a p. 26, HIRSCHMANN 1992b p. 98, WIŚNIEWSKI \& HIRSCHMANN 1993 p. 77, WIŚNIEWSKI 1993a p. 244, WIŚNIEWSKI 1993 b p. 396, KONTSCHÁN 2008 p. 29.

Elterjedés: Tanzánia.

\section{Rotundabaloghia (Circobaloghia) nguruensis HIRSCHMANN, 1992 (52. ábra)}

Rotundabaloghia nguruensis HIRSCHMANN: 1992a p. 37,Figs p. 38.

Rotundabaloghia nguruensis: HIRSCHMANN 1992a p. 26, HIRSCHMANN 1992d p. 97 , WIŚNIEWSKI \& HIRSCHMANN 1993 p. 74, WIŚNIEWSKI 1993a p. 246, WIŚNIEWSKI 1993 b p. 396, KONTSCHÁN 2008a p. 29, KONTSCHÁN 2010a p. 43.

Elterjedés: Tanzánia. 


\section{Rotundabaloghia (Circobaloghia) pocsi HIRSCHMANN, 1992 (53 ábra)}

Rotundabaloghia pocsi HIRSCHMANN: 1992a p. 31, Figs p. 33.

Rotundabaloghia pocsi: HIRSCHMANN 1992a p. 26, HIRSCHMANN 1992d p. 97, WIŚNIEWSKI \& HIRSCHMANN 1993 p. 74, WIŚNIEWSKI 1993a p. 246, WIŚNIEWSKI 1993b p. 396, KONTSCHÁN 2008a p. 29, KONTSCHÁN 2010a p. 43.

Elterjedés: Tanzánia.

\section{Rotundabaloghia (Circobaloghia) tanzaniae HIRSCHMANN, 1992 (54. ábra)}

Rotundabaloghia tanzaniae HIRSCHMANN: 1992a p. 31, Figs p. 33.

Rotundabaloghia tanzaniae: HIRSCHMANN 1992a p. 26, HIRSCHMANN 1992b p. 97, WIŚNIEWSKI \& HIRSCHMANN 1993 p. 74, WIŚNIEWSKi 1993a p. 246, WIŚNIEWSKI 1993 b p. 396, KONTSCHÁN 2008 p. 29, KONTSCHÁN 2010a p. 43.

Elterjedés: Tanzánia.

\section{Rotundabaloghia (Circobaloghia) meruensis HIRSCHMANN, 1992 (55. ábra)}

Rotundabaloghia meruensis HIRSCHMANN: 1992a p. 37, Figs p. 38.

Rotundabaloghia meruensis: HIRSCHMANN 1992a p. 26, HIRSCHMANN 1992d p. 97, WIŚNIEWSKI \& HIRSCHMANN 1993 p. 74, WIŚNIEWSKI 1993a p. 246, WIŚNIEWSKI 1993b p. 396, KONTSCHÁN 2008a p. 29, KONTSCHÁN 2010a p. 44.

Elterjedés: Tanzánia.

\section{Rotundabaloghia (Circobaloghia) africana HIRSCHMANN, 1992 (56. ábra)}

Rotundabaloghia africana HIRSCHMANN: 1992a p. 35, Figs p. 36.

Rotundabaloghia africana: HIRSCHMANN 1992a p. 25, HIRSCHMANN 1992d p. 97, WIŚNIEWSKI \& HIRSCHMANN 1993 p. 72, WIŚNIEWSKI 1993a p. 246, WIŚNIEWSKI 1993 b p. 394, KONTSCHÁN 2008a p. 29, KONTSCHÁN 2010a p. 44.

Elterjedés: Tanzánia.

\section{Rotundabaloghia (Circobaloghia) splendida KONTSCHÁN, 2008 (57. ábra)}

Rotundabaloghia splendida KONTSCHÁN: 2008a pp. 22-23, Figs 8-13.

Rotundabaloghia splendida: KONTSCHÁN 2008a p. 29, KONTSCHÁN 2010a p. 44.

Elterjedés: Tanzánia.

\section{Rotundabaloghia (Circobaloghia) kimbozae HIRSCHMANN, 1992 (58. ábra)}

Rotundabaloghia kimbozae HiRSCHMANN: 1992a p. 31, Figs p. 32.

Rotundabaloghia kimbozae: HiRSCHMANN 1992a p. 26, HiRSCHMANN 1992d p. 97, WIŚNIEWSKI \& HIRSCHMANN 1993 p. 79, WIŚNIEWSKI 1993a p. 246, WIŚNIEWSKI 1993 b p. 395, KONTSCHÁN 2008a p. 29, KONTSCHÁN 2010a p. 44.

Elterjedés: Tanzánia. 
Rotundabaloghia (Circobaloghia) lindqvisti HIRSCHMANN, 1992 (59. ábra)

Rotundabaloghia lindqvisti HIRSCHMANN: 1992a p. 31, Figs p. 32.

Rotundabaloghia lindqvisti: HIRSCHMANN 1992a p. 26, HIRSCHMANN 1992d p. 97, WIŚNIEWSKI \& HIRSCHMANN 1993 p. 79, WIŚNIEWSKI 1993a p. 246, WIŚNIEWSKI 1993 b p. 395, KONTSCHÁN 2008a p. 29, KONTSCHÁN 2010a p. 45.

Elterjedés: Tanzánia.

\section{Rotundabaloghia (Circobaloghia) lindqvistiformis KONTSCHÁN, 2008 (60. ábra)}

Rotundabaloghia lindqvistiformis KONTSCHÁN: 2008a pp. 23-25, Figs 14-18.

Rotundabaloghia lindqvistiformis: KONTSCHÁN 2008a p. 29, KONTSCHÁN 2010a p. 45.

Elterjedés: Tanzánia.
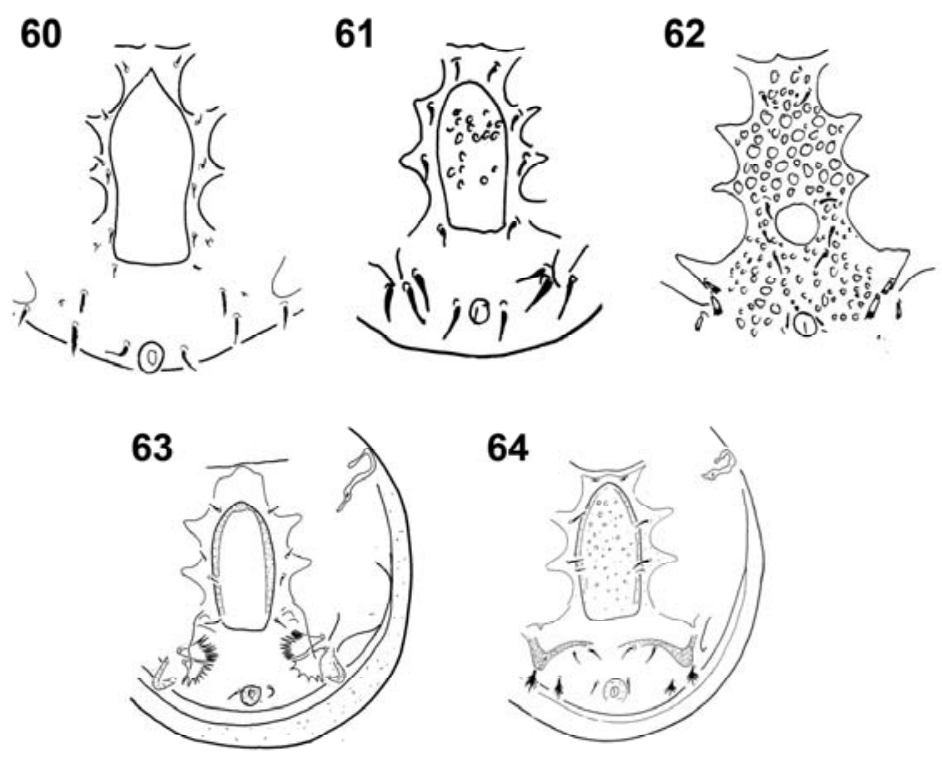

60-64. ábrák. A kelet-afrikai Rotundabaloghia (Circobaloghia) fajok hasi nézete a legfontosabb karakterekkel II.

Figures 60-64. Ventral aspect of the known East-African Rotundabaloghia (Circobaloghia) species II.

\section{Rotundabaloghia (Circobaloghia) mahunkaiana (KONTSCHÁN, 2006) (61. ábra)}

Rotundabaloghia mahunkaiana KONTSCHÁN: 2006 pp. 16-17, Figs 38-40.

Rotundabaloghia mahunkaiana: KONTSCHÁN 2010a p. 42.

Elterjedés: Angola. 
Rotundabaloghia (Circobaloghia) uluguruensis HIRSCHMANN, 1992 (62. ábra)

Rotundabaloghia uluguruensis HIRSCHMANN: 1992a p. 43, Figs p. 44.

Rotundabaloghia uluguruensis: HIRSCHMANN 1992a p. 26, HIRSCHMANN 1992d p. 98, WIŚNIEWSKI \& HIRSCHMANN 1993 p. 77, WIŚNIEWSKI 1993a p. 246, WIŚNIEWSKI 1993 b p. 396, KONTSCHÁN 2008a p. 29, KONTSCHÁN 2010a p. 42.

Elterjedés: Tanzánia.

Rotundabaloghia (Circobaloghia) stellata KONTSCHÁN, 2010 (63. ábra) Rotundabaloghia (Circobaloghia) stellata: KonTSCHÁN 2010a pp 47-48, Fig. 89. Elterjedés: Uganda.

\section{Rotundabaloghia (Circobaloghia) lineata KonTSCHÁN, 2010 (64. ábra)} Rotundabaloghia (Circobaloghia) lineata: KonTSCHÁn 2010a pp. 49-50, Fig. 90. Elterjedés: Kenya.

\section{Malgas szubrégió Rotundabaloghia (Circobaloghia) fajai}

Rotundabaloghia (Circobaloghia) benyovszkyi KONTSCHÁn, 2007 (65. ábra)

Rotundabaloghia benyovszkyi KONTSCHÁN: 2007 p.174, Figs 6-10.

Rotundabaloghia benyovszkyi: KONTSCHÁN 2010a p. 54.

Elterjedés: Madagaszkár.

Rotundabaloghia (Circobaloghia) madagascarensis KONTSCHÁN, 2007 (66. ábra)

Rotundabaloghia madagascarensis KonTSCHÁN: 2007 p.172, Figs 1-5.

Rotundabaloghia madagascarensis: KONTSCHÁN 2010a p. 54.

Elterjedés: Madagaszkár.

Rotundabaloghia (Circobaloghia) hauseri KonTSCHÁN, 2010 (67. ábra)

Rotundabaloghia hauseri KONTSCHÁN: 2010 pp. 55-56, Fig. 93.

Elterjedés: Madagaszkár.

Rotundabaloghia (Circobaloghia) ermilovi KONTSCHÁN \& STARÝ, 2014 (68. ábra) Rotundabaloghia ermilovi KONTSCHÁN \& STARÝ: 2014 pp. 563-565, Figs 60-74. Elterjedés: Madagaszkár. 

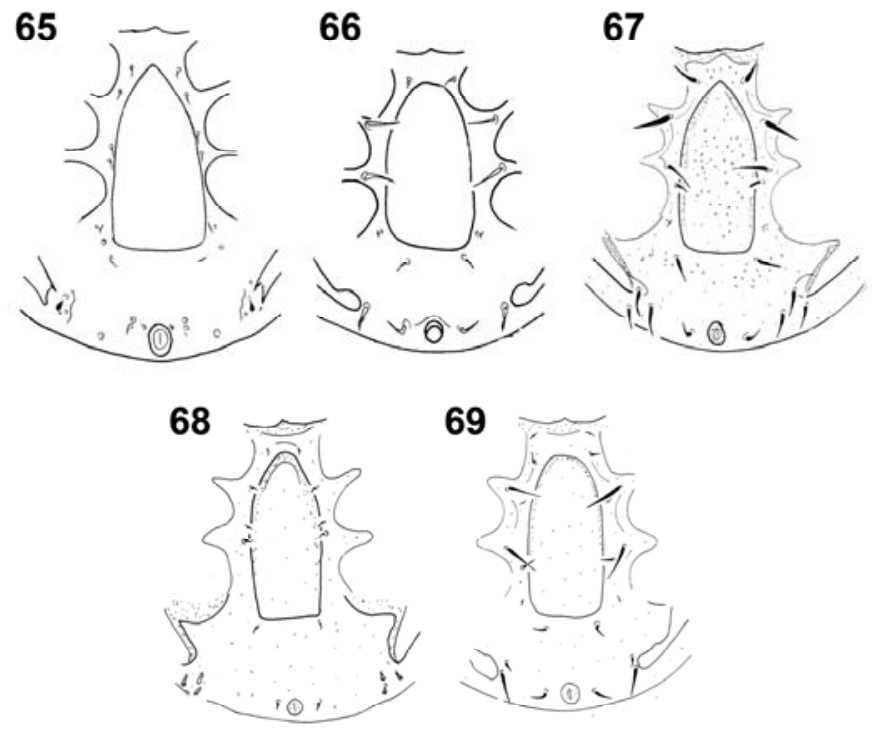

65-69. ábrák. A malgas Rotundabaloghia (Circobaloghia) fajok hasi nézete a legfontosabb karakterekkel.

Figures 65-69. Ventral aspect of the known malgas Rotundabaloghia (Circobaloghia) species.

Rotundabaloghia (Circobaloghia) kaydani KONTSCHÁN \& STARÝ, 2014 (69. ábra)

Rotundabaloghia kaydani KONTSCHÁN \& STARÝ: 2014 pp. 565-567, Figs 75-82.

Elterjedés: Madagaszkár.

\section{Neotrópikus régió Rotundabaloghia (Circobaloghia) fajai}

\section{Karib-szigetek szubrégió Rotundabaloghia (Circobaloghia) fajai}

\section{Rotundabaloghia (Circobaloghia) cubana KonTSCHÁN, 2007 (70. ábra)}

Rotundabaloghia cubana KONTSCHÁN: 2007a pp. 135-137, Figs 1-3.

Rotundabaloghia cubana: KONTSCHÁN 2010a p. 57.

Elterjedés: Kuba. 

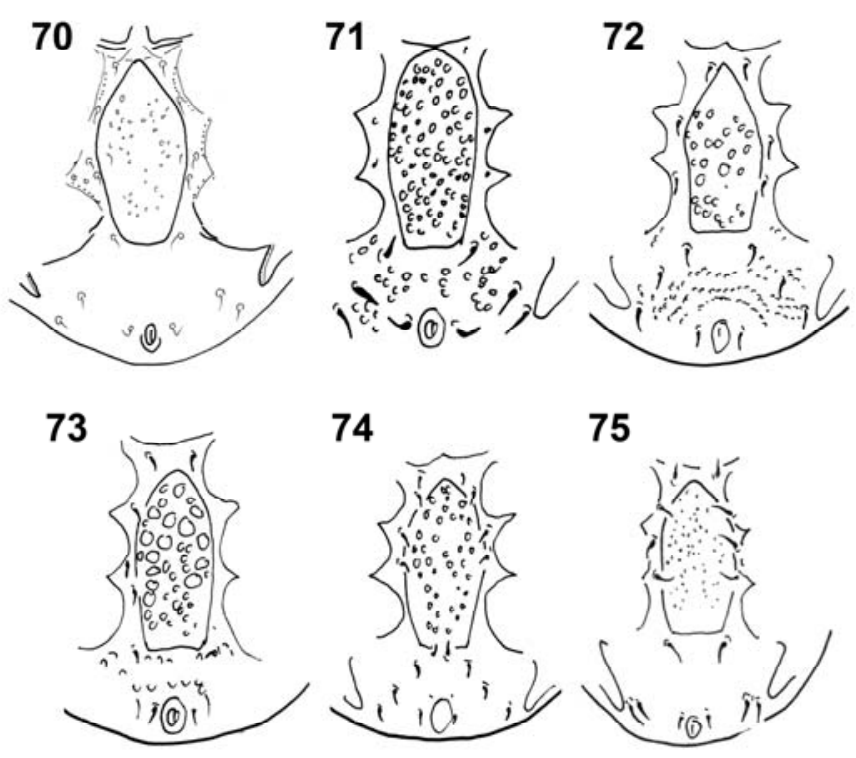

74

75

70-75. ábrák. A karib-szigeteki Rotundabaloghia (Circobaloghia) fajok hasi nézete a legfontosabb karakterekkel.

Figures 70-75. Ventral aspect of the known Caribean Rotundabaloghia (Circobaloghia) species.

\section{Rotundabaloghia (Circobaloghia) dominicana KONTSCHÁN, 2005 (71. ábra)}

Rotundabaloghia dominicana KonTSCHÁN: 2005 pp.242-243, Figs 1-4.

Rotundabaloghia dominicana: KONTSCHÁN 2007a p. 137, KONTSCHÁN 2010a p. 57.

Elterjedés: Dominikai Köztársaság.

\section{Rotundabaloghia (Circobaloghia) szuetsi KonTSCHÁN, 2005 (72. ábra)}

Rotundabaloghia szuetsi KonTSCHÁN: 2005 pp. 243-245, Figs 5-10.

Rotundabaloghia szuetsi: KONTSCHÁN 2007a p. 137, KONTSCHÁN 2010a p. 57.

Elterjedés: Dominikai Köztársaság.

\section{Rotundabaloghia (Circobaloghia) punctata KONTSCHÁN, 2005 (73. ábra)}

Rotundabaloghia punctata KONTSCHÁN: 2005 pp.245, Figs 11-12.

Rotundabaloghia punctata: KONTSCHÁN 2007a p. 137, KONTSCHÁN 2010a p. 57.

Elterjedés: Dominikai Köztársaság. 
Rotundabaloghia (Circobaloghia) arragensis KONTSCHÁN, 2005 (74. ábra)

Rotundabaloghia arragensis KONTSCHÁN: 2005 pp. 245-247, Figs 13-13.

Rotundabaloghia arragensis: KONTSCHÁN 2007a p. 137. KONTSCHÁN 2010a p. 58.

Elterjedés: Dominikai Köztársaság.

Rotundabaloghia (Circobaloghia) pocsiana KonTSCHÁN, 2005 (75. ábra)

Rotundabaloghia pocsiana KonTSCHÁN: 2005 pp. 247-248, Figs 15-17.

Rotundabaloghia pocsiana: KONTSCHÁN 2007a p. 137. KONTSCHÁN 2010a p. 58.

Elterjedés: Dominikai Köztársaság.

Kontinentális Neotrópus szubrégió Rotundabaloghia (Circobaloghia) fajai

Rotundabaloghia (Circobaloghia) australis HIRSCHMANN, 1992 (85. ábra)

Rotundabaloghia australis HIRSCHMANN: 1992c p. 86, Figs p. 85.

Rotundabaloghia australis: HIRSCHMANN 1992c p. 69, HIRSCHMANN 1992d p. 96, WIŚNIEWSKI \& HIRSCHMANN 1993 p. 71, WIŚNIEWSKI 1993b p. 394, KONTSCHÁN 2010a p. 59.

Elterjedés: Dél-Amerika.

Rotundabaloghia (Circobaloghia) boliviensis HIRSCHMANN, 1992 (86. ábra)

Rotundabaloghia boliviensis HIRSCHMANN: 1992c p. 90, Figs p. 89.

Rotundabaloghia boliviensis: HIRSCHMANN 1992c p. 69, HIRSCHMANN 1992d p. 97, WIŚNIEWSKI \& HIRSCHMANN 1993 p. 79, WIŚNIEWSKI 1993a p. 230, WIŚNIEWSKI 1993 b p. 394, KONTSCHÁN 2010a p. 59.

Elterjedés: Bolívia.

Rotundabaloghia (Circobaloghia) coroicoensis HIRSCHMANN, 1981 (76. ábra)

Rotundabaloghia coroicoensis HIRSCHMANN: 1981 p. 121, Fig. 56.

Rotundabaloghia coroicoensis: HIRSCHMANN 1992c p. 69, HIRSCHMANN 1992d p. 96, WIŚNIEWSKI \& HIRSCHMANN 1993 p. 71, WIŚNIEWSKI 1993a p. 230, WIŚNIEWSKI 1993 b p. 395, KONTSCHÁN 2010a p. 59.

Elterjedés: Bolívia.

\section{Rotundabaloghia (Circobaloghia) manausensis HiRSCHMANN, 1992 (77. ábra)}

Rotundabaloghia manausensis HIRSCHMANN: 1992c p. 86, Figs p. 86.

Rotundabaloghia manausensis: HIRSCHMANN 1992c p. 70, HIRSCHMANN 1992d p. 96, WIŚNIEWSKI \& HIRSCHMANN 1993 p. 72, WIŚNIEWSKI 1993a p. 232, WIŚNIEWSKI 1993 b p. 396, KONTSCHÁN 2010a p. 59.

Rotundabaloghia (Circobaloghia) maculosa HIRSCHMANN, 1992 (syn: KONTSCHÁN 2010a)

Rotundabaloghia maculosa HIRSCHMANN: 1992c p. 87, Figs p. 87. 
Rotundabaloghia maculosa: HIRSCHMANN 1992c p. 70, HIRSCHMANN 1992d p. 96, WIŚNIEWSKI \& HIRSCHMANN 1993 pp. 71-72, WIŚNIEWSKI 1993a p. 239, WIŚNIEWSKI 1993 b p. 395.

Elterjedés: Brazília és Ecuador.

\section{Rotundabaloghia (Circobaloghia) rotunda (HIRSCHMANN, 1973) (78. ábra)}

Uroobovella rotunda HIRSCHMANN: 1973 pp. 166-167, Fig. 114.

Rotundabaloghia rotunda: HIRSCHMANN 1992c p. 70, HIRSCHMANN 1992d p. 97, WIŚNIEWSKI \& HIRSCHMANN 1993 p. 74, WIŚNIEWSKI 1993a p. 232, WIŚNIEWSKI 1993 b p. 396, KONTSCHÁN 2009 p. 388, KONTSCHÁN 2010a p. 60.

Elterjedés: Brazília.

\section{Rotundabaloghia (Circobaloghia) uncinata (HIRSCHMANN \& ZIRNGIEBL-NICOL, 1962)} (79. ábra)

Uroobovella uncinata HIRSCHMANN: 1962 pp. 73-74, Figs 22: 20, 26: 2.

Uroobovella uncinata: WIŚNIEWSKI 1993a p. 234.

Rotundabaloghia uncinata: HIRSCHMANN 1992c p. 70, HIRSCHMANN 1992d p. 97, WIŚNIEWSKI \& HIRSCHMANN 1993 p. 78, WIŚNIEWSKI 1993b p. 395, KONTSCHÁN 2010a p. 60.

Elterjedés: Brazília.

\section{Rotundabaloghia (Circobaloghia) guttaseta (HIRSCHMANN \& ZIRNGIEBL-NICOL, 1972)} (80. ábra)

Uroobovella guttaseta HIRSCHMANN: 1972 p. 115, Fig. 93.

Uroobovella guttaseta: WIŚNIEWSKI 1993a p. 234.

Rotundabaloghia guttaseta: HIRSCHMANN 1992c p. 69, HIRSCHMANN 1992d p. 97, WIŚNIEWSKI \& HIRSCHMANN 1993 p. 78, WIŚNIEWSKI 1993b p. 395, KONTSCHÁN 2009 p. 388, KONTSCHÁN 2010a p. 61.

Elterjedés: Brazília.

\section{Rotundabaloghia (Circobaloghia) hexaunguiseta HIRSCHMANN, 1992 (88. ábra)}

Rotundabaloghia hexaunguiseta HIRSCHMANN: 1992c p. 77, Figs p. 76.

Rotundabaloghia hexaunguiseta: HIRSCHMANN 1992c p. 69, HIRSCHMANN 1992d p. 97 , WIŚNIEWSKI \& HIRSCHMANN 1993 p. 78, WIŚNIEWSKI 1993a p. 246, WIŚNIEWSKI 1993 b p. 395, KONTSCHÁN 2009 p. 388, KONTSCHÁN 2010a p. 61.

Elterjedés: Brazília. 
76

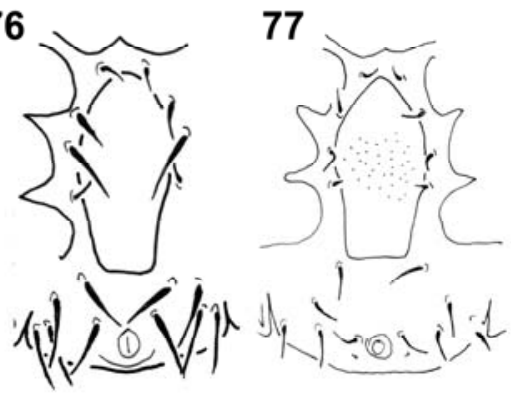

78

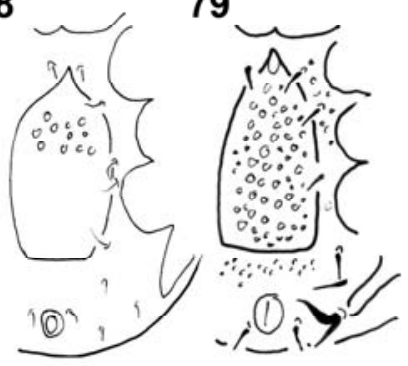

80

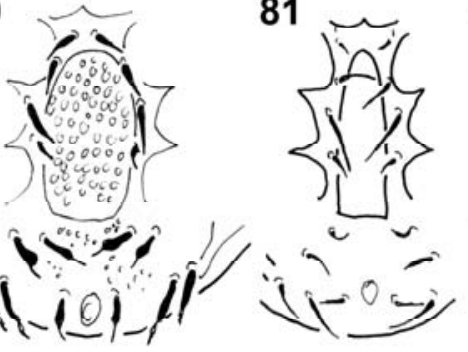

82

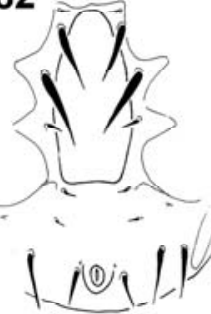

83
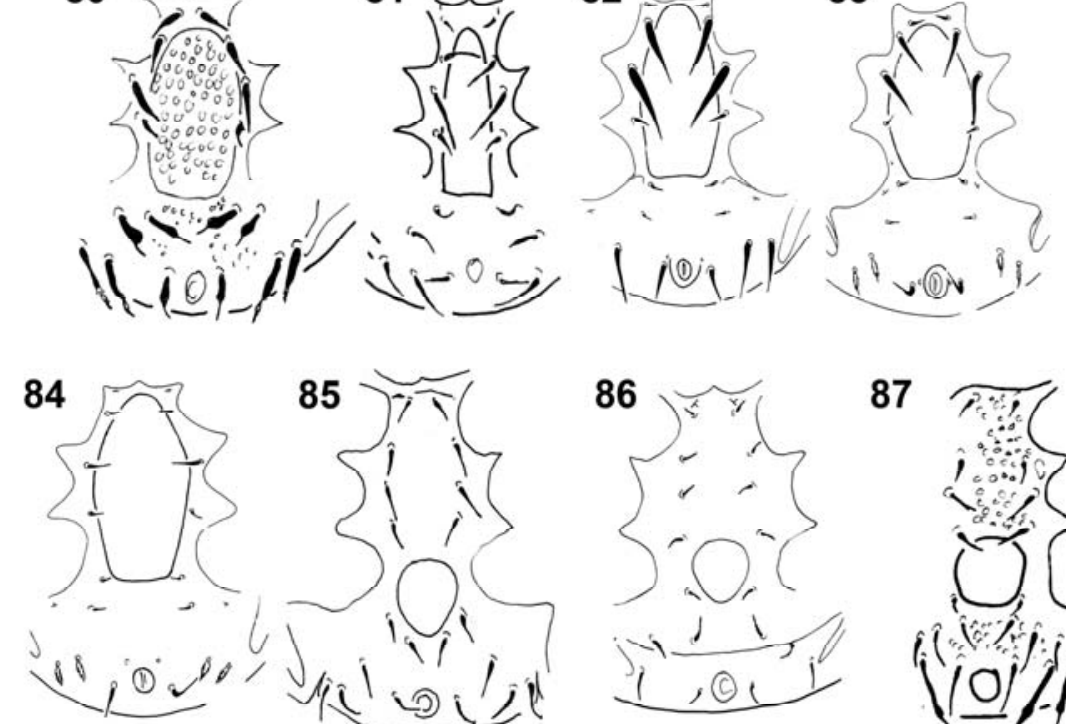

87

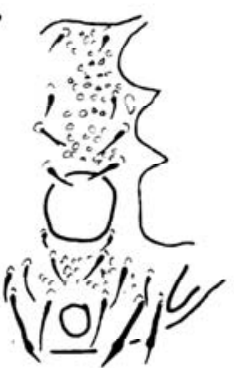

88

89

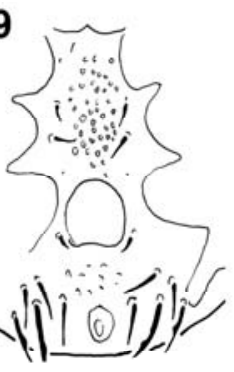

90

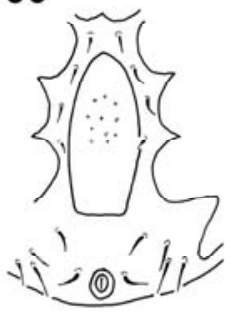

91

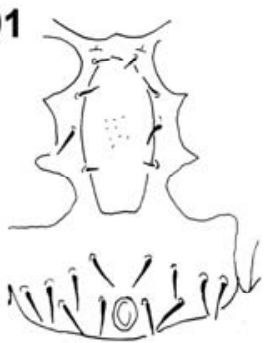

76-91. ábrák. A neotrópusi Rotundabaloghia (Circobaloghia) fajok hasi nézete a legfontosabb karakterekkel I.

Figures 76-91. Ventral aspect of the known Neotropical Rotundabaloghia (Circobaloghia) species I. 
Rotundabaloghia (Circobaloghia) tetraunguiseta HIRSCHMANN, 1992 (87. ábra)

Rotundabaloghia tetraunguiseta HIRSCHMANN: 1992c p. 76, Figs p. 76.

Rotundabaloghia tetraunguiseta: HIRSCHMANN 1992c p. 70, HIRSCHMANN 1992d p. 97 , WIŚNIEWSKI \& HIRSCHMANN 1993 p. 78, WIŚNIEWSKI 1993b p. 396, KONTSCHÁN 2010a p. 61.

Elterjedés: Brazília.

Rotundabaloghia (Circobaloghia) unguiseta (HIRSCHMANN \& ZIRNGIEBL-NICOL, 1972) (89. ábra)

Uroobovella unguiseta HIRSCHMANN: 1972c pp. 115-116, Fig. 94.

Uroobovella unquiseta (sic!): WIŚNIEWSKI 1993a p. 234.

Rotundabaloghia unguiseta: HIRSCHMANN 1992c p. 70, HIRSCHMANN 1992d p. 97, WIŚNIEWSKI \& HIRSCHMANN 1993 p. 78, WIŚNIEWSKI 1993b p. 396, KONTSCHÁN 2009 p. 388, KONTSCHÁN 2010a p. 61.

Elterjedés: Brazília.

Rotundabaloghia (Circobaloghia) woelkei HIRSCHMANN, 1981 (81. ábra)

Rotundabaloghia woelkei HIRSCHMANN: 1981 p. 121-122, Figs 57.

Rotundabaloghia woelkei: HIRSCHMANN 1992c p. 70, HIRSCHMANN 1992b p. 97, WIŚNIEWSKI \& HIRSCHMANN 1993 p. 80, WIŚNIEWSKI 1993a p. 232, WIŚNIEWSKI 1993 b p. 396, KONTSCHÁn 2009 p. 389, KONTSCHÁN 2010a p. 62.

Elterjedés: Brazília.

Rotundabaloghia (Circobaloghia) traseri KONTSCHÁN, 2009 (82. ábra)

Rotundabaloghia traseri KONTSCHÁN: 2009c pp. 386-388, Figs 9-12.

Rotundabaloghia traseri: KONTSCHÁN 2009c p. 389, KONTSCHÁN 2010a p. 62.

Elterjedés: Brazília.

Rotundabaloghia (Circobaloghia) gigantea KONTSCHÁN, 2009 (83. ábra)

Rotundabaloghia gigantea KONTSCHÁN: 2009c pp. 384-386, Figs 5-8. Rotundabaloghia gigantea: KONTSCHÁN 2009c p. 389, KONTSCHÁN 2010a p. 64.

Elterjedés: Brazília.

\section{Rotundabaloghia (Circobaloghia) brasiliensis KONTSCHÁN, 2009 (84. ábra)}

Rotundabaloghia brasiliensis KonTSCHÁN: 2009c pp. 382-384, Figs 1-4. Rotundabaloghia brasiliensis: KONTSCHÁN 2009c p. 389, KONTSCHÁN 2010a p. 64.

Elterjedés: Brazília. 
Rotundabaloghia (Circobaloghia) altoensis HIRSCHMANN, 1992 (90. ábra)

Rotundabaloghia altoensis HIRSCHMANN: 1992 p. 65, Figs p. 66.

Rotundabaloghia altoensis: HIRSCHMANN 1992b p. 26, HIRSCHMANN 1992d p. 97, WIŚNIEWSKI \& HIRSCHMANN 1993 p. 72, WIŚNIEWSKI 1993a p. 235, WIŚNIEWSKI 1993 b p. 394, KONTSCHÁN 2010a p. 65.

Elterjedés: Kolumbia.

\section{Rotundabaloghia (Circobaloghia) amazonasae HIRSCHMANN, 1992 (91. ábra)}

Rotundabaloghia amazonasae HIRSCHMANN: 1992b p. 59, Figs p. 60.

Rotundabaloghia amazonasae: HIRSCHMANN 1992b p. 45, HIRSCHMANN 1992 p. 96, WIŚNIEWSKI \& HIRSCHMANN 1993 p. 71, WIŚNIEWSKI 1993a p. 234, WIŚNIEWSKI 1993 b p. 394, KONTSCHÁN 2010a p. 65.

Elterjedés: Kolumbia.

\section{Rotundabaloghia (Circobaloghia) bosqueensis HIRSCHMANN, 1992 (92. ábra)}

Rotundabaloghia bosqueensis HIRSCHMANN: 1992b p. 67, Figs p. 67.

Rotundabaloghia bosqueensis: HIRSCHMANN 1992b p. 45, HIRSCHMANN 1992d p. 97 , WIŚNIEWSKI \& HIRSCHMANN 1993 p. 74, WIŚNIEWSKI 1993a p. 235, WIŚNIEWSKI 1993 b p. 394, KONTSCHÁN 2010a p. 65.

Elterjedés: Kolumbia.

Rotundabaloghia (Circobaloghia) extremica KonTSCHÁn, 2008 (93. ábra)

Rotundabaloghia extremica KONTSCHÁN: 2008c p. 37, Figs 61-67.

Rotundabaloghia extremica: KONTSCHÁN 2010a p. 65.

Elterjedés: Kolumbia.

\section{Rotundabaloghia (Circobaloghia) chingazaensis HiRSCHMANN, 1992 (94. ábra)}

Rotundabaloghia chingazaensis HiRSCHMANN: 1992b p. 63, Figs p. 64.

Rotundabaloghia chingazaensis: HIRSCHMANN 1992b p. 45, HIRSCHMANN 1992d p. 97 , WIŚNIEWSKI \& HIRSCHMANN 1993 p. 72, WIŚNIEWSKI 1993a p. 235, WIŚNIEWSKI 1993 b p. 394, KONTSCHÁN 2010a p. 66.

Elterjedés: Kolumbia.

\section{Rotundabaloghia (Circobaloghia) chisacaensis HiRSCHMANN, 1992 (95. ábra)}

Rotundabaloghia chisacaensis HIRSCHMANN: 1992b p. 57, Figs p. 58.

Rotundabaloghia chisacaensis: HIRSCHMANN 1992b p. 45, HIRSCHMANN 1992d p. 97, WIŚNIEWSKI \& HIRSCHMANN 1993 p. 73, WIŚNIEWSKI 1993a p. 235, WIŚNIEWSKI 1993b p. 394, KONTSCHÁN 2010a p. 66.

Elterjedés: Kolumbia. 

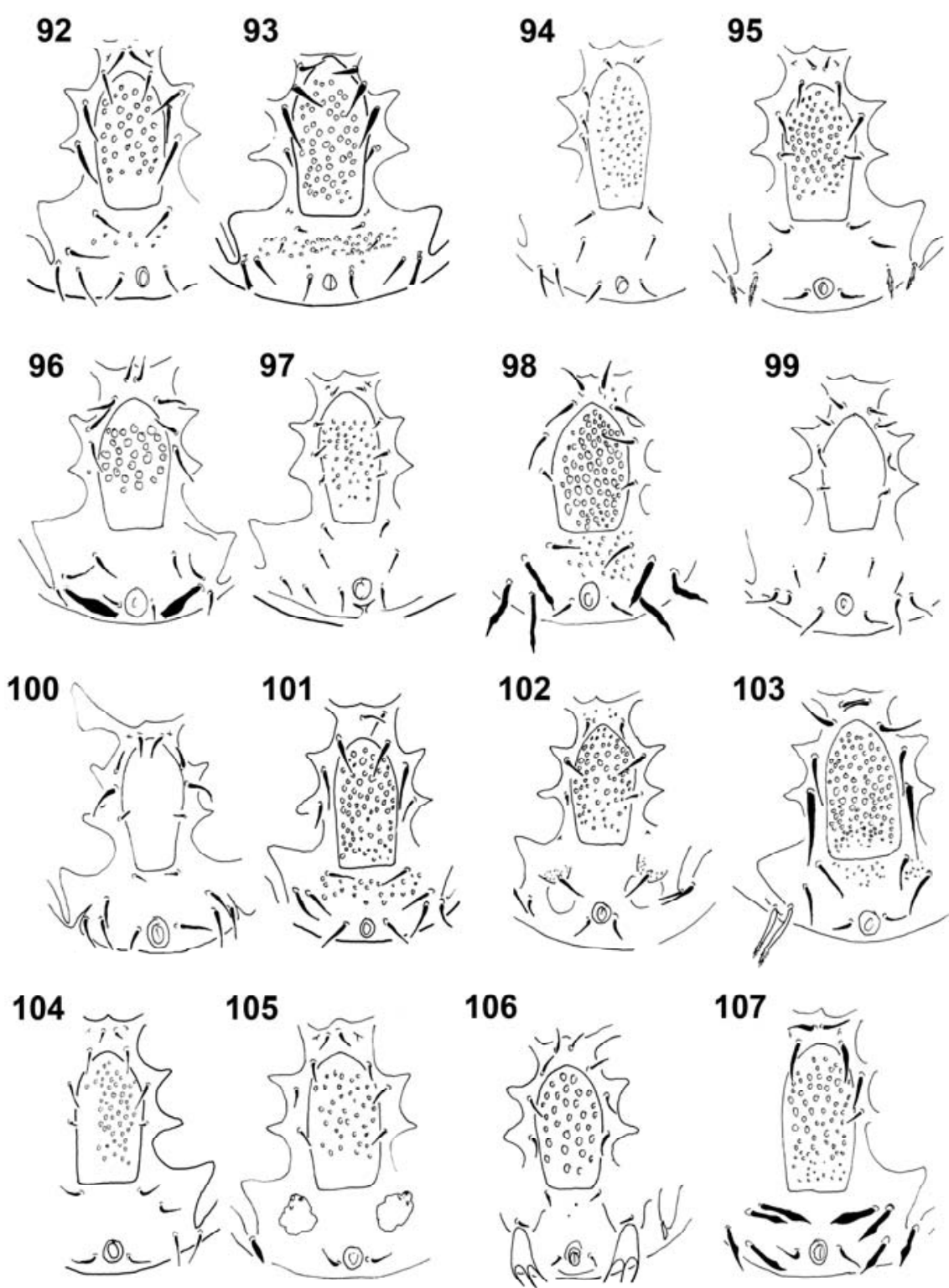

92-107. ábrák. A neotrópusi Rotundabaloghia (Circobaloghia) fajok hasi nézete a legfontosabb karakterekkel II.

Figures 92-107. Ventral aspect of the known Neotropical Rotundabaloghia (Circobaloghia) species II. 
Rotundabaloghia (Circobaloghia) diclavata HIRSCHMANN, 1992 (96. ábra)

Rotundabaloghia diclavata HIRSCHMANN: 1992b p. 55, Figs p. 56.

Rotundabaloghia diclavata: HIRSCHMANN 1992b p. 45, HIRSCHMANN 1992d p. 97, WIŚNIEWSKI \& HIRSCHMANN 1993 p. 78, WIŚNIEWSKI 1993a p. 235, WIŚNIEWSKI 1993b p. 394, KONTSCHÁN 2010a p. 66.

Elterjedés: Kolumbia.

\section{Rotundabaloghia (Circobaloghia) flava HiRSCHMANN, 1992 (97. ábra)}

Rotundabaloghia flava HIRSCHMANN: 1992b p. 31, Figs p. 32.

Rotundabaloghia flava: HIRSCHMANN 1992b p. 69, HIRSCHMANN 1992d p. 97, WIŚNIEWSKI \& HIRSCHMANN 1993 p. 73, WIŚNIEWSKI 1993a p. 235, WIŚNIEWSKI 1993 b p. 395, KONTSCHÁN 2010a p. 66.

Elterjedés: Kolumbia.

\section{Rotundabaloghia (Circobaloghia) hexaspinosa HIRSCHMANN, 1992 (98. ábra)}

Rotundabaloghia hexaspinosa HiRSCHMANN: 1992b p. 53, Figs p. 54.

Rotundabaloghia hexaspinosa: HIRSCHMANN 1992b p. 46, HIRSCHMANN 1992d p. 97 , WIŚNIEWSKI \& HIRSCHMANN 1993 p. 78, WIŚNIEWSKI 1993a p. 235, WIŚNIEWSKI 1993 b p. 395, KONTSCHÁN 2010a p. 67.

Elterjedés: Kolumbia.

\section{Rotundabaloghia (Circobaloghia) huilae HiRSCHMANN, 1992 (99. ábra)}

Rotundabaloghia huilae HIRSCHMANN: 1992b p. 63, Figs p. 62.

Rotundabaloghia huilae: HIRSCHMANN 1992b p. 46, HIRSCHMANN 1992d p. 97, WIŚNIEWSKI \& HIRSCHMANN 1993 p. 79, WIŚNIEWSKI 1993a p. 235, WIŚNIEWSKI 1993 b p. 395, KONTSCHÁN 2010a p. 67.

Elterjedés: Kolumbia.

\section{Rotundabaloghia (Circobaloghia) leteciae HIRSCHMANN, 1992 (100. ábra)}

Rotundabaloghia leteciae HIRSCHMANN: 1992b p. 59, Figs p. 60.

Rotundabaloghia leteciae: HIRSCHMANN 1992b p. 46, HIRSCHMANN 1992d p. 96, WIŚNIEWSKI \& HIRSCHMANN 1993 p. 71, WIŚNIEWSKI 1993a p. 235, WIŚNIEWSKI 1993 b p. 395, KONTSCHÁN 2010a p. 67.

Rotundabaloghia (Circobaloghia) leteciasimilis HIRSCHMANN, 1992 (syn: KONTSCHÁN 2010a)

Rotundabaloghia leteciasimilis HIRSCHMANN: 1992b p. 59, Figs p. 60.

Rotundabaloghia leteciasimilis: HIRSCHMANN 1992b p. 46, HIRSCHMANN 1992d p. 96, WIŚNIEWSKI \& HIRSCHMANN 1993 p. 71, WIŚNIEWSKI 1993a p. 235, WIŚNIEWSKI 1993 b p. 395.

Elterjedés: Kolumbia. 
Rotundabaloghia (Circobaloghia) guerreroensis HIRSCHMANN, 1992 (101. ábra)

Rotundabaloghia guerreroensis HIRSCHMANN: 1992b p. 67, Figs p. 68.

Rotundabaloghia guerreroensis: HIRSCHMANN 1992b p. 46, HIRSCHMANN 1992d p. 97 , WIŚNIEWSKI \& HIRSCHMANN 1993 p. 75, WIŚNIEWSKI 1993a p. 235, WIŚNIEWSKI 1993 b p. 395, KONTSCHÁN 2010a p. 68.

Elterjedés: Kolumbia.

\section{Rotundabaloghia (Circobaloghia) lamellosa HiRSCHMANN, 1992 (102. ábra)}

Rotundabaloghia lamellosa HiRSCHMANN: 1992b p. 50, Figs p. 51.

Rotundabaloghia lamellosa: HIRSCHMANN 1992b p. 26, HIRSCHMANN 1992d p. 97, WIŚNIEWSKI \& HIRSCHMANN 1993 p. 77, WIŚNIEWSKI 1993a p. 235, WIŚNIEWSKI 1993 b p. 395, KONTSCHÁN 2010a p. 68.

Elterjedés: Kolumbia.

\section{Rotundabaloghia (Circobaloghia) monserratensis HIRSCHMANN, 1992 (103. ábra)}

Rotundabaloghia monserratensis HIRSCHMANN: 1992b p. 59, Figs p. 58.

Rotundabaloghia monserratensis: HIRSCHMANN 1992b p. 46, HIRSCHMANN 1992d p. 98, WIŚNIEWSKI \& HIRSCHMANN 1993 p. 77, WIŚNIEWSKI 1993a p. 235, WIŚNIEWSKI 1993 b p. 396, KONTSCHÁN 2010a p. 68.

Elterjedés: Kolumbia.

\section{Rotundabaloghia (Circobaloghia) pajonalis HiRSCHMANN, 1992 (104. ábra)}

Rotundabaloghia pajonalis HIRSCHMANN: 1992b p. 65, Figs p. 66.

Rotundabaloghia pajonalis: HIRSCHMANN 1992b p. 46, HIRSCHMANN 1992d p. 97, WIŚNIEWSKI \& HIRSCHMANN 1993 p. 74, WIŚNIEWSKI 1993a p. 235, WIŚNIEWSKI 1993 b p. 39b, KONTSCHÁN 2010a p. 68.

Elterjedés: Kolumbia.

\section{Rotundabaloghia (Circobaloghia) pituitosa HIRSCHMANN, 1992 (105. ábra)}

Rotundabaloghia pituitosa HIRSCHMANN: 1992b p. 52, Figs p. 52.

Rotundabaloghia pituitosa: HIRSCHMANN 1992b p. 46, HIRSCHMANN 1992d p. 97, WIŚNIEWSKI \& HIRSCHMANN 1993 p. 74, WIŚNIEWSKI 1993a p. 235, WIŚNIEWSKI 1993 b p. 396, KONTSCHÁN 2010a p. 69.

Elterjedés: Kolumbia.

Rotundabaloghia (Circobaloghia) sturmi HIRSCHMANN, 1984 (106. ábra)

Rotundabaloghia sturmi HIRSCHMANN: 1984 p. 28, Figs p. 28.

Rotundabaloghia sturmi: HIRSCHMANN 1992b p. 46, HIRSCHMANN 1992d p. 97, WIŚNIEWSKI \& HIRSCHMANN 1993 p. 78, WIŚNIEWSKI 1993a p. 235, WIŚNIEWSKI 1993 b p. 396, KONTSCHÁN 2010a p. 70.

Elterjedés: Kolumbia. 


\section{Rotundabaloghia (Circobaloghia) octospinosa HIRSCHMANN, 1992 (107. ábra)}

Rotundabaloghia octospinosa HIRSCHMANN: 1992b p. 53, Figs p. 55.

Rotundabaloghia octospinosa: HIRSCHMANN 1992b p. 46, HIRSCHMANN 1992d p. 97 , WIŚNIEWSKI \& HIRSCHMANN 1993 p. 78, WIŚNIEWSKI 1993a p. 235, WIŚNIEWSKI 1993 b p. 396, KONTSCHÁN 2010a p. 70.

Elterjedés: Kolumbia.

\section{Rotundabaloghia (Circobaloghia) silvacola HIRSCHMANN, 1992 (108. ábra)}

Rotundabaloghia silvacola HIRSCHMANN: 1992b p. 63, Figs p. 64.

Rotundabaloghia silvacola: HIRSCHMANN 1992b p. 46, HIRSCHMANN 1992d p. 97, WIŚNIEWSKI \& HIRSCHMANN 1993 p. 74, WIŚNIEWSKI 1993a p. 235, WIŚNIEWSKI 1993 b p. 396, KONTSCHÁN 2010a p. 70.

Rotundabaloghia humicola HIRSCHMANN, 1992 (syn: KONTSCHÁN 2010a)

Rotundabaloghia humicola HIRSCHMANN: 1992b p. 63, Figs p. 65.

Rotundabaloghia humicola: HIRSCHMANN 1992b p. 46, HIRSCHMANN 1992d p. 97, WIŚNIEWSKI \& HIRSCHMANN 1993 p. 73, WIŚNIEWSKI 1993a p. 235, WIŚNIEWSKI 1993 b p. 395.

Elterjedés: Kolumbia.

\section{Rotundabaloghia (Circobaloghia) tetraclavata HIRSCHMANN, 1992 (109. ábra)}

Rotundabaloghia tetraclavata HiRSCHMANN: 1992 p. 55, Figs p. 56.

Rotundabaloghia tetraclavata: HiRSCHMANN 1992b p. 24, HIRSCHMANN 1992d p. 97, WIŚNIEWSKI \& HIRSCHMANN 1993 p. 78, WIŚNIEWSKI 1993a p. 235, WIŚNIEWSKI 1993 b p. 396, KONTSCHÁN 2010a p. 71.

Elterjedés: Kolumbia.

\section{Rotundabaloghia (Circobaloghia) belemensis HIRSCHMANN, 1992 (110. ábra)}

Rotundabaloghia belemensis HIRSCHMANN: 1992b p. 57, Figs p. 57.

Rotundabaloghia belemensis: HIRSCHMANN 1992b p. 45, HIRSCHMANN 1992d p. 98, WIŚNIEWSKI \& HIRSCHMANN 1993 p. 77, WIŚNIEWSKI 1993a p. 235, WIŚNIEWSKI 1993b p. 394, KONTSCHÁN 2010a p. 71.

Elterjedés: Kolumbia.

\section{Rotundabaloghia (Circobaloghia) monterredondoensis HIRSCHMANN, 1992 (111. ábra)}

Rotundabaloghia monterredondoensis HIRSCHMANN: 1992b p. 61, Figs p. 62.

Rotundabaloghia monterredondoensis: HIRSCHMANN 1992b p. 46, HIRSCHMANN 1992d p. 97, WIŚNIEWSKI \& HIRSCHMANN 1993 p. 74, WIŚNIEWSKI 1993a p. 235, WiŚNIEWSKI 1993b p. 396, KONTSCHÁN 2010a p. 71.

Elterjedés: Kolumbia. 
108

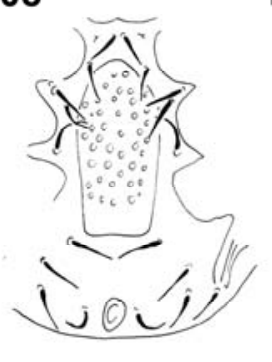

109

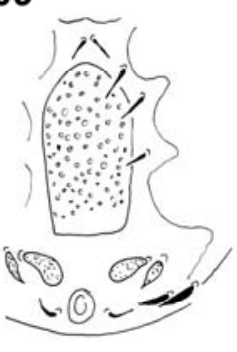

112

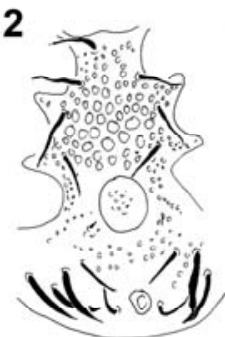

113

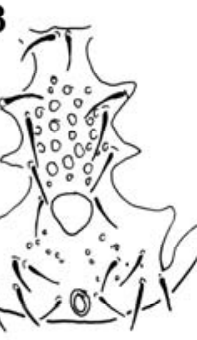

110

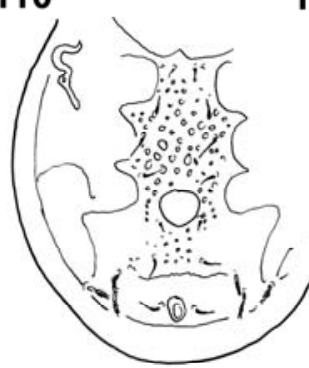

114

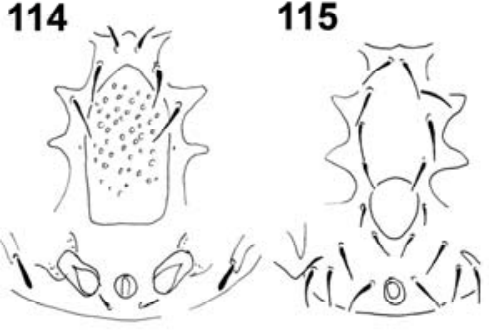

116

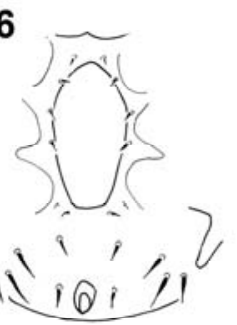

117

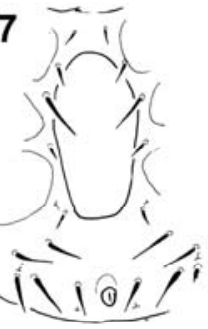

118

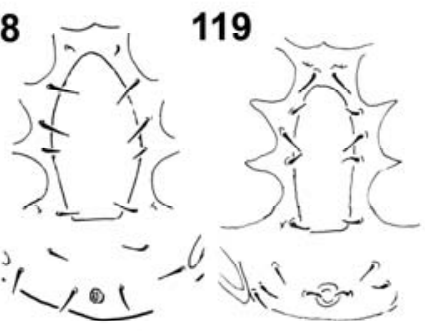

120

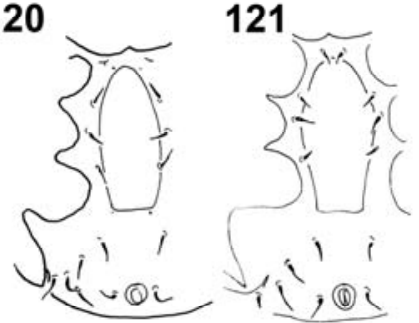

122

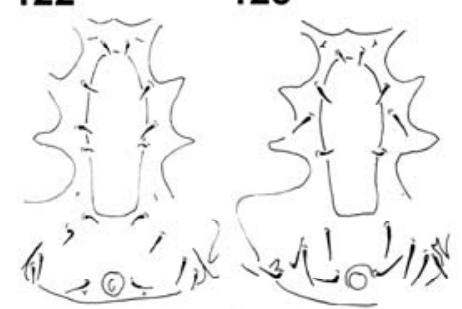

108-123. ábrák. A neotrópusi Rotundabaloghia (Circobaloghia) fajok hasi nézete a legfontosabb karakterekkel III.

Figure 108-123. Ventral aspect of the known Neotropical Rotundabaloghia (Circobaloghia) species III. 


\section{Rotundabaloghia (Circobaloghia) sexpinosa HIRSCHMANN, 1992 (112. ábra)}

Rotundabaloghia sexpinosa HIRSCHMANN: 1992b p. 53, Figs p. 55.

Rotundabaloghia sexpinosa: HIRSCHMANN 1992b p. 46, HIRSCHMANN 1992d p. 97 , WIŚNIEWSKI \& HIRSCHMANN 1993 p. 78, WIŚNIEWSKI 1993a p. 235, WIŚNIEWSKI 1993 b p. 396, KONTSCHÁN 2010a p. 71.

Elterjedés: Kolumbia.

\section{Rotundabaloghia (Circobaloghia) fincae HIRSCHMANN, 1992 (113. ábra)}

Rotundabaloghia fincae HIRSCHMANN: 1992 b p. 68, Figs p. 68.

Rotundabaloghia fincae: HIRSCHMANN 1992b p. 46, HIRSCHMANN 1992d p. 97, WIŚNIEWSKI \& HIRSCHMANN 1993 p. 75, WIŚNIEWSKI 1993a p. 235, WIŚNIEWSKI 1993 b p. 395, KONTSCHÁN 2010a p. 72.

Rotundabaloghia (Circobaloghia) huallagae HIRSCHMANN, 1992 (syn: KONTSCHÁN 2010a)

Rotundabaloghia huallagae HIRSCHMANN: 1992c p. 93, Figs p. 93.

Rotundabaloghia huallagae: HIRSCHMANN 1992c p. 69, HIRSCHMANN 1992d p. 97, WIŚNIEWSKI \& HIRSCHMANN 1993 p. 75, WIŚNIEWSKI 1993a p. 240, WIŚNIEWSKI 1993 b p. 395.

Elterjedés: Kolumbia és Peru.

\section{Rotundabaloghia (Circobaloghia) forcipata HIRSCHMANN, 1992 (114. ábra)}

Rotundabaloghia forcipata HIRSCHMANN: 1992b p. 50, Figs p. 51.

Rotundabaloghia forcipata: HIRSCHMANN 1992b p. 46, HIRSCHMANN 1992d p. 97, WIŚNIEWSKI \& HIRSCHMANN 1993 p. 77, WIŚNIEWSKI 1993a p. 235, WIŚNIEWSKI 1993 b p. 395, KONTSCHÁN 2010a p. 72.

Elterjedés: Kolumbia.

\section{Rotundabaloghia (Circobaloghia) taguae HIRSCHMANN, 1992 (115. ábra)}

Rotundabaloghia taguae HIRSCHMANN: 1992b p. 61, Figs p. 61.

Rotundabaloghia taguae: HIRSCHMANN 1992b p. 46, HIRSCHMANN 1992d p. 96, WIŚNIEWSKI \& HIRSCHMANN 1993 p. 72, WIŚNIEWSKI 1993a p. 235, WIŚNIEWSKI 1993 b p. 396, KONTSCHÁN 2010a p. 72.

Elterjedés: Kolumbia.

\section{Rotundabaloghia (Circobaloghia) resinae Hirschmann, 1992 (116. ábra)}

Rotundabaloghia resinae HIRSCHMANN: 1992b p. 63, Figs p. 62.

Rotundabaloghia resinae: HIRSCHMANN 1992b p. 46, HIRSCHMANN 1992d p. 97, WIŚNIEWSKI \& HIRSCHMANN 1993 p. 79, WIŚNIEWSKI 1993a p. 235, WIŚNIEWSKI 1993 b p. 396, KONTSCHÁN 2008c p. 34-35. KONTSCHÁN 2010a p. 73.

Elterjedés: Kolumbia. 
Rotundabaloghia (Circobaloghia) coricoensiformis KONTSCHÁN, 2008 (117. ábra)

Rotundabaloghia coricoensiformis KONTSCHÁN: 2008c pp. 34-36, Figs 58-60.

Rotundabaloghia coricoensiformis: KONTSCHÁN 2010a p. 73.

Elterjedés: Kolumbia.

Rotundabaloghia (Circobaloghia) unisetosa KonTSCHÁn, 2009 (118. ábra)

Rotundabaloghia unisetosa KONTSCHÁN: 2009d p. 25, Figs 3-9.

Rotundabaloghia unisetosa: KonTSCHÁN 2010a p. 74.

Elterjedés: Costa Rica.

\section{Rotundabaloghia (Circobaloghia) baczaensis HIRSCHMANN, 1992 (119. ábra)}

Rotundabaloghia baczaensis HIRSCHMANN: 1992c p. 85, Figs p. 84.

Rotundabaloghia baczaensis: HIRSCHMANN 1992c p. 69, HIRSCHMANN 1992d p. 96, WIŚNIEWSKI \& HIRSCHMANN 1993 p. 71, WIŚNIEWSKI 1993a p. 239, WIŚNIEWSKI 1993 b p. 394, KONTSCHÁN 2008c pp. 25-28, KONTSCHÁN 2010a p. 75.

Rotundabaloghia (Circobaloghia) linguaeformis HIRSCHMANN, 1992 (syn: KONTSCHÁN 2010a)

Rotundabaloghia linguaeformis HiRSCHMANN: 1992c p. 85, Figs p. 84.

Rotundabaloghia linguaeformis: HIRSCHMANN 1992c p. 70, HIRSCHMANN 1992d p. 96, WIŚNIEWSKI \& HIRSCHMANN 1993 p. 71, WIŚNIEWSKI 1993a p. 239, WIŚNIEWSKI 1993 b p. 395.

Elterjedés: Ecuador.

\section{Rotundabaloghia (Circobaloghia) duodecimventralis HiRSCHMANN, 1992 (120. ábra)}

Rotundabaloghia duodecimventralis HiRSCHMANN: 1992c p. 80, Figs p. 79.

Rotundabaloghia duodecimventralis: HIRSCHMANN 1992c p. 69, HIRSCHMANN 1992d p. 96, WIŚNIEWSKI \& HIRSCHMANN 1993 p. 71, WIŚNIEWSKI 1993a p. 239, WIŚNIEWSKI 1993b p. 395, KONTSCHÁN 2010a p. 75.

Elterjedés: Ecuador.

\section{Rotundabaloghia (Circobaloghia) magna HIRSCHMANN, 1992 (121. ábra)}

Rotundabaloghia magna HIRSCHMANN: 1992c p. 81, Figs p. 81.

Rotundabaloghia magna: HIRSCHMANN 1992c p. 70, HIRSCHMANN 1992d p. 96, WIŚNIEWSKI \& HIRSCHMANN 1993 p. 72, WIŚNIEWSKI 1993a p. 239, WIŚNIEWSKI 1993b p. 395, KONTSCHÁN 2010a p. 75.

Rotundabaloghia (Circobaloghia) picchuensis HIRSCHMANN, 1992 (syn: KONTSCHÁN 2010a)

Rotundabaloghia picchuensis HIRSCHMANN: 1992c p. 86, Figs p. 85.

Rotundabaloghia picchuensis: HIRSCHMANN 1992c p. 70, HIRSCHMANN 1992d p. 96, WIŚNIEWSKI \& HIRSCHMANN 1993 p. 72, WIŚNIEWSKI 1993a p. 240, WIŚNIEWSKi 1993 b. 396. 
Rotundabaloghia (Circobaloghia) quitoensis HIRSCHMANN, 1992 (syn: KONTSCHÁN 2010a)

Rotundabaloghia quitoensis HIRSCHMANN: 1992c p. 81, Figs p. 81.

Rotundabaloghia quitoensis: HIRSCHMANN 1992c p. 70, HIRSCHMANN 1992d p. 96, WIŚNIEWSKI \& HIRSCHMANN 1993 p. 72, WIŚNIEWSKI 1993a p. 239, WIŚNIEWSKI 1993 b p. 396.

Rotundabaloghia (Circobaloghia) vonalis HIRSCHMANN, 1992 (syn: KONTSCHÁN 2010a)

Rotundabaloghia vonalis HIRSCHMANN: 1992c p. 88, Figs p. 88.

Rotundabaloghia vonalis: HIRSCHMANN 1992c p. 70, HIRSCHMANN 1992d p. 97, WIŚNIEWSKI \& HIRSCHMANN 1993 p. 80, WIŚNIEWSKI 1993a p. 240, WIŚNIEWSKI 1993 b p. 396.

Elterjedés: Ecuador és Peru.

\section{Rotundabaloghia (Circobaloghia) soliformis HiRSCHMANN, 1992 (122. ábra)}

Rotundabaloghia soliformis HIRSCHMANN: 1992c p. 82, Figs p. 82.

Rotundabaloghia soliformis: HIRSCHMANN 1992c p. 70, HIRSCHMANN 1992d p. 96, WIŚNIEWSKI \& HIRSCHMANN 1993 p. 72, WIŚNIEWSKI 1993a p. 239, WIŚNIEWSKI 1993 b p. 396, KONTSCHÁN 2008c p. 25, KONTSCHÁN 2010a p. 76.

Elterjedés: Ecuador.

\section{Rotundabaloghia (Circobaloghia) soliformoides HIRSCHMANN, 1992 (123. ábra)}

Rotundabaloghia soliformoides HIRSCHMANN: 1992c p. 80, Figs p. 80.

Rotundabaloghia soliformoides: HIRSCHMANN 1992c p. 70, HIRSCHMANN 1992d p. 96, WIŚNIEWSKI \& HIRSCHMANN 1993 p. 72, WIŚNIEWSKI 1993a p. 239, WIŚNIEWSKI 1993 b p. 396, KONTSCHÁN 2010a p. 76.

Elterjedés: Ecuador.

\section{Rotundabaloghia (Circobaloghia) ecuadorensis HIRSCHMANN, 1992 (124. ábra)}

Rotundabaloghia ecuadorensis HIRSCHMANN: 1992c p. 91, Figs p. 92.

Rotundabaloghia ecuadorensis: HIRSCHMANN 1992c p. 69, HIRSCHMANN 1992d p. 97, WIŚNIEWSKI \& HIRSCHMANN 1993 p. 73, WIŚNIEWSKI 1993a p. 239, WIŚNIEWSKI 1993 b p. 396, KONTSCHÁN 2008c pp. 27-28, KONTSCHÁN 2010a p. 77.

Elterjedés: Ecuador.

\section{Rotundabaloghia (Circobaloghia) maculosoides HIRSCHMANN, 1992 (125. ábra)}

Rotundabaloghia maculosoides HIRSCHMANN: 1992c p. 92, Figs p. 92.

Rotundabaloghia maculosoides: HIRSCHMANN 1992c p. 70, HIRSCHMANN 1992d p. 97, WIŚNIEWSKI \& HIRSCHMANN 1993 p. 73, WIŚNIEWSKI 1993a p. 239, WIŚNIEWSKI 1993 b p. 395, KONTSCHÁN 2010a p. 77.

Elterjedés: Ecuador. 
124

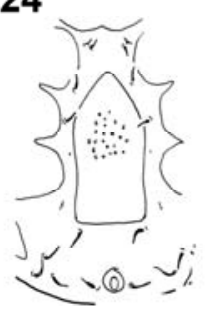

125

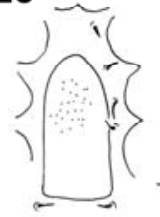

- 0 ( ) 少

128

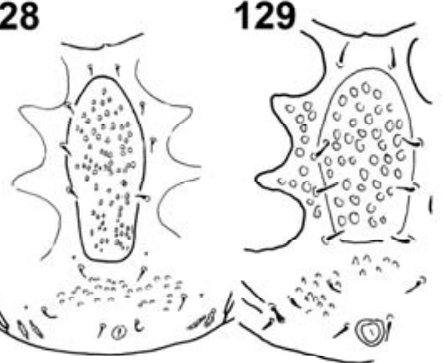

132

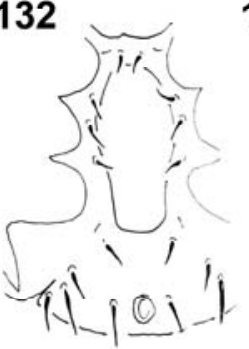

133

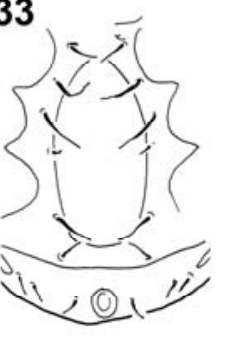

136

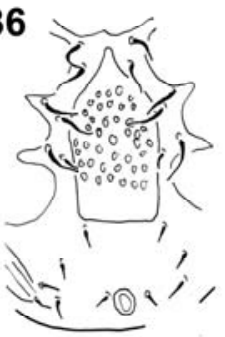

137

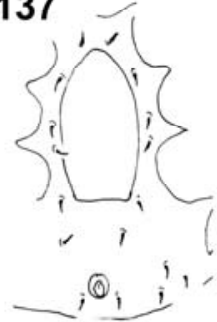

126

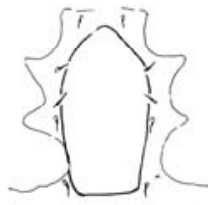

边, 公

130

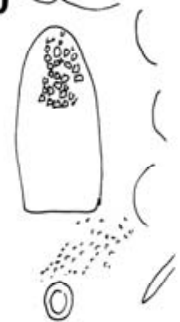

134

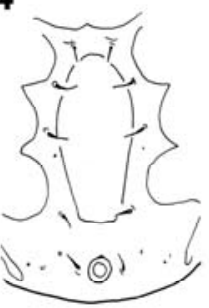

138
127
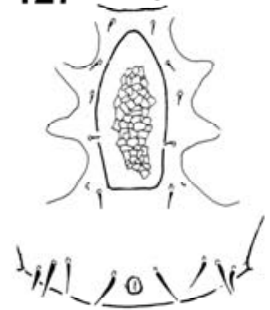

131

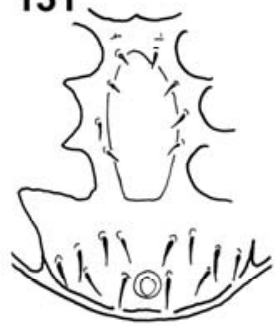

135

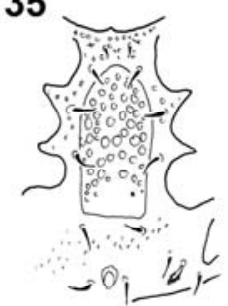

139

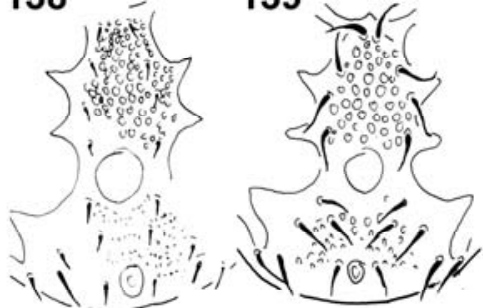

124-139. ábrák. A neotrópusi Rotundabaloghia (Circobaloghia) fajok hasi nézete a legfontosabb karakterekkel IV.

Figures 124-139. Ventral aspect of the known Neotropical Rotundabaloghia (Circobaloghia) species IV. 
Rotundabaloghia (Circobaloghia) zicsiana KoNTSCHÁN, 2008 (126. ábra)

Rotundabaloghia zicsiana KONTSCHÁN: 2008c pp.245, Figs 42-45.

Rotundabaloghia zicsiana: KONTSCHÁN 2010a p. 77.

Elterjedés: Ecuador.

\section{Rotundabaloghia (Circobaloghia) reticuloides KONTSCHÁN, 2008 (127. ábra)}

Rotundabaloghia reticuloides KONTSCHÁN: 2008c p. 28, Figs 42-45.

Rotundabaloghia reticuloides: KONTSCHÁN 2010a p. 77.

Elterjedés: Ecuador.

\section{Rotundabaloghia (Circobaloghia) ecuadorica KonTSCHÁn, 2008 (128. ábra)}

Rotundabaloghia ecuadorica KONTSCHÁN: 2008c pp. 31-33, Figs 50-53.

Rotundabaloghia ecuadorica: KONTSCHÁN 2010a p. 78.

Elterjedés: Ecuador.

\section{Rotundabaloghia (Circobaloghia) ovaligynella HIRSCHMANN, 1992 (129. ábra)}

Rotundabaloghia ovaligynella HiRSCHMANN: 1992c p. 78, Figs p. 78.

Rotundabaloghia ovaligynella: HIRSCHMANN 1992c p. 70, HIRSCHMANN 1992d p. 97, WIŚNIEWSKI \& HIRSCHMANN 1993 p. 76, WIŚNIEWSKI 1993a p. 239, WIŚNIEWSKI 1993b p. 396. KONTSCHÁN 2010a p. 78.

Elterjedés: Ecuador.

\section{Rotundabaloghia (Circobaloghia) guatemalae HIRSCHMANN, 1992 (130. ábra)}

Rotundabaloghia guatemalae HIRSCHMANN: 1992c p. 95, Figs p. 95.

Rotundabaloghia guatemalae: HIRSCHMANN 1992c p. 69, HIRSCHMANN 1992d p. 97 , WIŚNIEWSKI \& HIRSCHMANN 1993 p. 75, WIŚNIEWSKI 1993a p. 226, WIŚNIEWSKI 1993 b p. 395, KONTSCHÁN 2010a p. 79.

Elterjedés: Guatemala.

\section{Rotundabaloghia (Circobaloghia) duodecimsetae HIRSCHMANN, 1992 (131. ábra)}

Rotundabaloghia duodecimsetae HIRSCHMANN: 1992c p. 80, Figs p. 79.

Rotundabaloghia duodecimsetae: HIRSCHMANN 1992c p. 69, HIRSCHMANN 1992d p. 96, WIŚNIEWSKI \& HIRSCHMANN 1993 p. 71, WIŚNIEWSKI 1993a p. 240, WIŚNIEWSKI 1993 b p. 395, KONTSCHÁN 2010a p. 79.

Rotundabaloghia duodecimtricha HIRSCHMANN, 1992 (syn: KONTSCHÁN 2010a)

Rotundabaloghia duodecimtricha HIRSCHMANN: 1992c p. 80, Figs p. 79.

Rotundabaloghia duodecimtricha: HIRSCHMANN 1992c p. 69, HIRSCHMANN 1992d p. 96, WIŚNIEWSKI \& HIRSCHMANN 1993 p. 71, WIŚNIEWSKI 1993a p. 240, WIŚNIEWSKI 1993 b p. 395.

Elterjedés: Peru. 
Rotundabaloghia (Circobaloghia) incisa HIRSCHMANN, 1992 (132. ábra)

Rotundabaloghia incisa HIRSCHMANN: 1992c p. 83, Figs p. 83.

Rotundabaloghia incisa: HIRSCHMANN 1992c p. 69, HIRSCHMANN 1992d p. 96, WIŚNIEWSKI \& HIRSCHMANN 1993 p. 71, WIŚNIEWSKI 1993a p. 240, WIŚNIEWSKI 1993 b p. 395, KONTSCHÁN 2010a p. 79.

Rotundabaloghia incisasimilis HIRSCHMANN, 1992 (syn: KonTSCHÁN 2010a)

Rotundabaloghia incisasimilis HIRSCHMANN: 1992c p. 83, Figs p. 83.

Rotundabaloghia incisasimilis: HIRSCHMANN 1992c p. 69, HIRSCHMANN 1992d p. 96, WIŚNIEWSKI \& HIRSCHMANN 1993 p. 71, WIŚNIEWSKI 1993a p. 240, WIŚNIEWSKI 1993 b p. 395.

Elterjedés: Peru.

\section{Rotundabaloghia (Circobaloghia) iquitosensis HIRSCHMANN, 1992 (133. ábra)}

Rotundabaloghia iquitosensis HIRSCHMANN: 1992c p. 90, Figs p. 89.

Rotundabaloghia iquitosensis: HIRSCHMANN 1992c p. 70, HIRSCHMANN 1992d p. 97, WIŚNIEWSKI \& HIRSCHMANN 1993 p. 79, WIŚNIEWSKI 1993a p. 240, WIŚNIEWSKI 1993 b p. 395, KONTSCHÁN 2010a p. 80.

Elterjedés: Peru.

\section{Rotundabaloghia (Circobaloghia) iquitosensoides HIRSCHMANN, 1992 (134. ábra)}

Rotundabaloghia iquitosensoides HIRSCHMANN: 1992c p. 90, Figs p. 90.

Rotundabaloghia iquitosensoides: HIRSCHMANN 1992c p. 70, HIRSCHMANN 1992d p. 97, WIŚNIEWSKI \& HIRSCHMANN 1993 p. 79, WIŚNIEWSKI 1993a p. 240, WIŚNIEWSKI 1993 b p. 395.

Elterjedés: Peru.

\section{Rotundabaloghia (Circobaloghia) limae HIRSCHMANN, 1992 (135. ábra)}

Rotundabaloghia limae HIRSCHMANN: 1992c p. 77, Figs p. 77.

Rotundabaloghia limae: HIRSCHMANN 1992c p. 70, HIRSCHMANN 1992d p. 97, WIŚNIEWSKI \& HIRSCHMANN 1993 p. 76, WIŚNIEWSKI 1993a p. 240, WIŚNIEWSKI 1993 b p. 395, KONTSCHÁN 2010a p. 80.

Elterjedés: Peru.

\section{Rotundabaloghia (Circobaloghia) pucallpae HIRSCHMANN, 1992 (136. ábra)}

Rotundabaloghia pucallpae HIRSCHMANN: 1992c p. 91, Figs p. 91.

Rotundabaloghia pucallpae: HIRSCHMANN 1992c p. 70, HIRSCHMANN 1992d p. 97, WIŚNIEWSKI \& HIRSCHMANN 1993 p. 74, WIŚNIEWSKI 1993a p. 240, WIŚNIEWSKI 1993 b p. 396, KONTSCHÁN 2010a p. 81.

Elterjedés: Peru. 
Rotundabaloghia (Circobaloghia) ucayali HIRSCHMANN, 1992 (137. ábra)

Rotundabaloghia ucayali HIRSCHMANN: 1992c p. 87, Figs p. 88.

Rotundabaloghia ucayali: HIRSCHMANN 1992c p. 70, HIRSCHMANN 1992d p. 97, WIŚNIEWSKI \& HIRSCHMANN 1993 p. 79, WIŚNIEWSKI 1993a p. 240, WIŚNIEWSKI 1993 b p. 396, KONTSCHÁN 2010a p. 81.

Elterjedés: Peru.

\section{Rotundabaloghia (Circobaloghia) peruensis HIRSCHMANN, 1992 (138. ábra)}

Rotundabaloghia peruensis HIRSCHMANN: 1992c p. 94, Figs p. 94.

Rotundabaloghia peruensis: HIRSCHMANN 1992c p. 70, HIRSCHMANN 1992d p. 97, WIŚNIEWSKI \& HIRSCHMANN 1993 p. 76, WIŚNIEWSKI 1993a p. 240, WIŚNIEWSKI 1993 b p. 396, KONTSCHÁN 2010a p. 81.

Elterjedés: Peru.

\section{Rotundabaloghia (Circobaloghia) cajamarcae HIRSCHMANN, 1992 (139. ábra)}

Rotundabaloghia cajamarcae HIRSCHMANN: 1992c p. 93, Figs p. 94.

Rotundabaloghia cajamarcae: HIRSCHMANN 1992c p. 69, HIRSCHMANN 1992d p. 97 , WIŚNIEWSKI \& HIRSCHMANN 1993 p. 74, WIŚNIEWSKI 1993a p. 240, WIŚNIEWSKI 1993 b p. 394, KONTSCHÁN 2010a p. 81.

Rotundabaloghia moyobambae HIRSCHMANN, 1992 (syn: KONTSCHÁN 2010a)

Rotundabaloghia moyobambae HIRSCHMANN: 1992c p. 93, Figs p. 94.

Rotundabaloghia moyobambae: HiRSCHMANN 1992c p. 70, HiRSCHMANN 1992d p. 97, WIŚNIEWSKI \& HIRSCHMANN 1993 p. 76, WIŚNIEWSKI 1993a p. 240, WIŚNIEWSKI 1993 b p. 396.

Elterjedés: Peru.

\section{Rotundabaloghia (Circobaloghia) magnioperculi HIRSCHMANN, 1992 (140. ábra)}

Rotundabaloghia magnioperculi HIRSCHMANN: 1992c p. 83, Figs p. 82.

Rotundabaloghia magnioperculi: HIRSCHMANN 1992c p. 70, HIRSCHMANN 1992d p. 96, WIŚNIEWSKI \& HIRSCHMANN 1993 p. 72, WIŚNIEWSKI 1993b p. 395, KONTSCHÁN 2010a p. 82.

Elterjedés: Peru.

\section{Rotundabaloghia (Circobaloghia) maranonensis HIRSCHMANN, 1992 (141. ábra)}

Rotundabaloghia maranonensis HIRSCHMANN: 1992c p. 93, Figs p. 92.

Rotundabaloghia maranonensis: HIRSCHMANN 1992c p. 70, HIRSCHMANN 1992d p. 97 , WIŚNIEWSKI \& HIRSCHMANN 1993 p. 73, WIŚNIEWSKI 1993a p. 240, WIŚNIEWSKI 1993 b p. 396, KONTSCHÁN 2010a p. 82.

Elterjedés: Peru. 
Rotundabaloghia (Circobaloghia) mahunkana KoNTSCHÁN, 2007 (142. ábra)

Rotundabaloghia mahunkana KonTSCHÁN: 2007a pp.342-345, Figs 16-22.

Rotundabaloghia mahunkana: KONTSCHÁN 2010a p. 83.

Elterjedés: Venezuela.

Rotundabaloghia (Circobaloghia) venezuelae HIRSCHMANN, 1992 (143. ábra)

Rotundabaloghia venezuelae HIRSCHMANN: 1992c p. 88, Figs p. 89.

Rotundabaloghia venezuelae: HIRSCHMANN 1992c p. 70, HIRSCHMANN 1992d p. 97,

WIŚNIEWSKI \& HIRSCHMANN 1993 pp. 79-80, WIŚNIEWSKI 1993a p. 237,

WIŚNIEWSKI 1993b p. 396, KONTSCHÁN 2010a p. 84.

Elterjedés: Venezuela.

Rotundabaloghia (Circobaloghia) panamana KonTSCHÁN, 2010 (144. ábra)

Rotundabaloghia (Circobaloghia) panamana KONTSCHÁn: 2010a pp. 84-85, Figs 168.

Elterjedés: Panama.

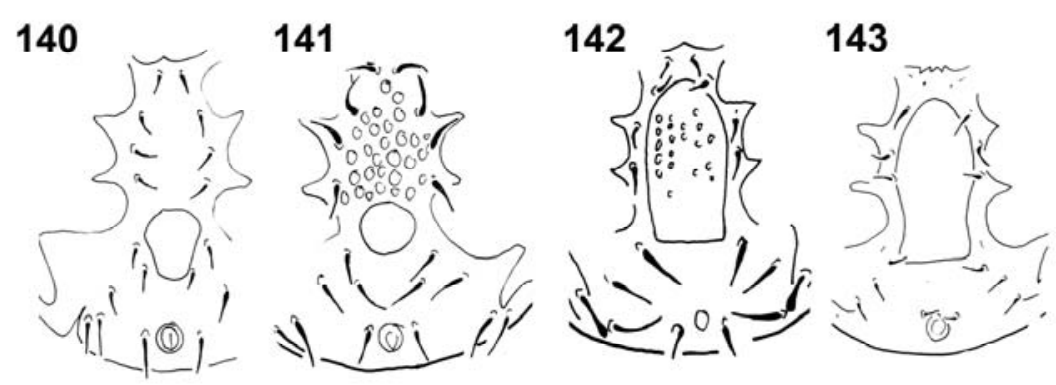

144

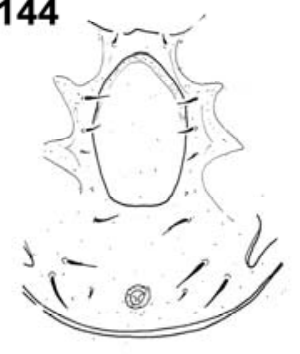

145

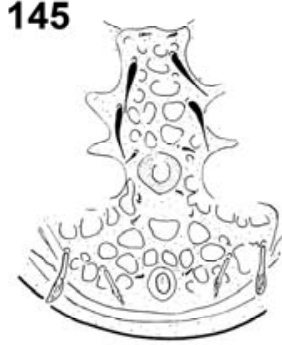

146

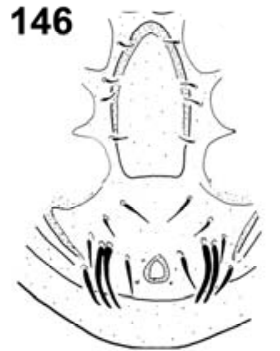

140-146. ábrák. A neotrópusi Rotundabaloghia (Circobaloghia) fajok hasi nézete a legfontosabb karakterekkel V.

Figures 140-146. Ventral aspect of the known Neotropical Rotundabaloghia (Circobaloghia) species IV. 
Rotundabaloghia (Circobaloghia) mexicana KONTSCHÁN, 2010 (145. ábra)

Rotundabaloghia (Circobaloghia) mexicana KonTSCHÁn: 2010a pp. 86-87, Figs 169.

Elterjedés: Mexikó.

Rotundabaloghia (Circobaloghia) lazoki KONTSCHÁN, 2010 (146. ábra)

Rotundabaloghia (Circobaloghia) lazoki KonTSCHÁN: 2010a pp. 88-89, Figs 170.

Elterjedés: Brazília.

Ausztrálázsiai és az Orientális régiók Rotundabaloghia (Circobaloghia) fajai

Rotundabaloghia (Circobaloghia) portaligynella HIRSCHMANN, 1975 (147. ábra)

Rotundabaloghia portaligynella HIRSCHMANN: 1975c p. 30, Figs 25.

Rotundabaloghia portaligynella: HIRSCHMANN \& HIRAMATSU 1992 p. 10, HIRSCHMANN 1992d p. 96, WIŚNIEWSKI \& HIRSCHMANN 1993 p. 70, WIŚNIEWSKI 1993a p. 282, WIŚNIEWSKI 1993b p. 396, KONTSCHÁN 2010a p. 96.

Elterjedés: Új-Guinea.

Rotundabaloghia (Circobaloghia) heterospinosa HiRsChMANN, 1975 (148. ábra)

Rotundabaloghia heteropsinosa HIRSCHMANN: 1975c p. 29, Figs 22.

Rotundabaloghia heterospinosa: HIRSCHMANN \& HIRAMATSU 1992 p. 10, HIRSCHMANN 1992d p. 98, WIŚNIEWSKI \& HIRSCHMANN 1993 p. 77, WIŚNIEWSKI 1993a p. 282, WIŚNIEWSKI 1993b p. 395, KONTSCHÁN 2010a p. 96.

Elterjedés: Új-Guinea.

Rotundabaloghia (Circobaloghia) zicsii HIRSCHMANN, 1975 (149. ábra)

Rotundabaloghia zicsii HIRSCHMANN: 1975a p. 32, Figs 31.

Rotundabaloghia zicsii: HIRSCHMANN \& HIRAMATSU 1992 p. 10, HIRSCHMANN 1992d p. 97, WIŚNIEWSKI \& HIRSCHMANN 1993 p. 76, WIŚNIEWSKI 1993a p. 282, WIŚNIEWSKI 1993b p. 396, KONTSCHÁN 2010a p. 96.

Elterjedés: Új-Guinea.

Rotundabaloghia (Circobaloghia) foraminosa HIRAMATsu, 1983 (150. ábra)

Rotundabaloghia foraminosa HIRAMATsu: 1983 pp. 123-128, Figs 14-24.

Rotundabaloghia foraminosa: HiRSCHMANN \& HIRAMATSU 1992 p. 10, HIRSCHMANN 1992d p. 96, WIŚNIEWSKI \& HIRSCHMANN 1993 p. 70, WIŚNIEWSKI 1993a p. 280, WIŚNIEWSKI 1993b p. 395, KONTSCHÁN 2010a p. 97.

Elterjedés: Indonézia, Borneó. 

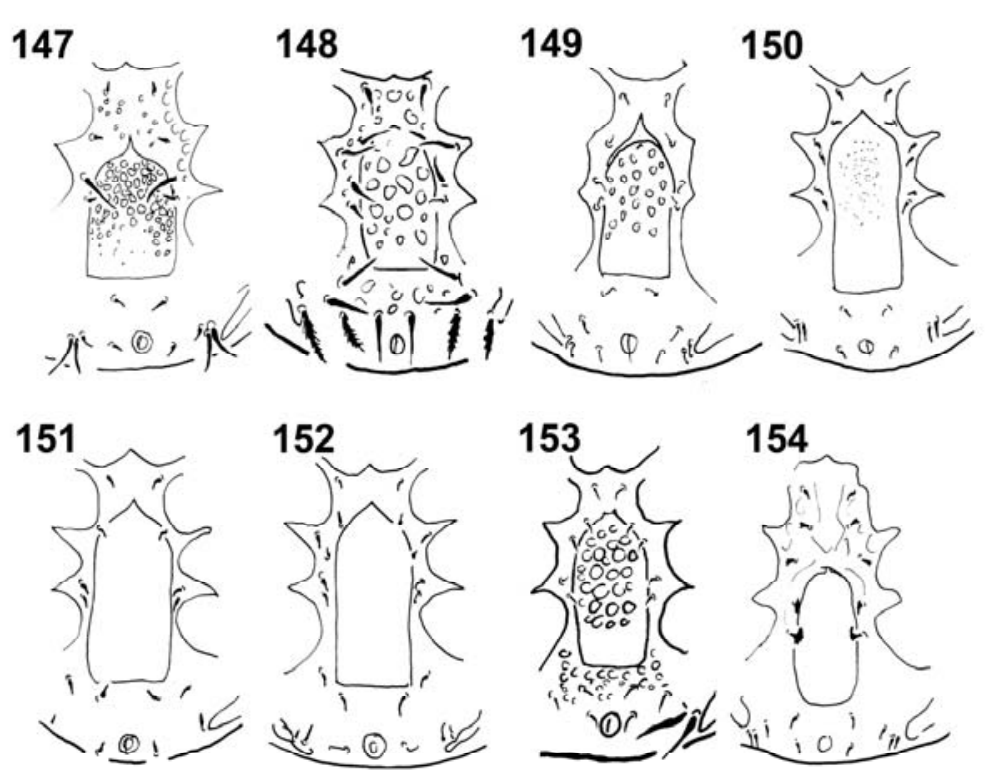

153

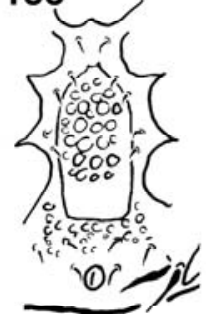

154

155

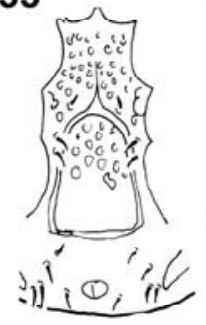

156

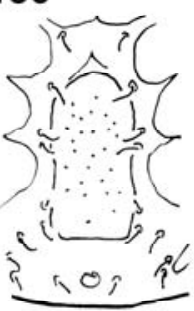

157

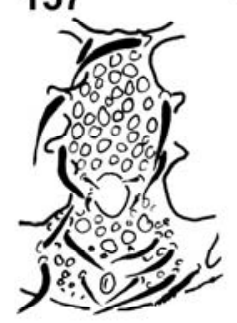

158

159

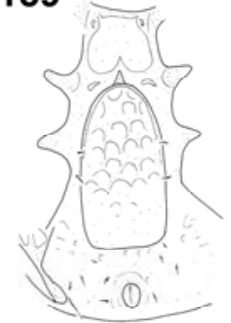

160

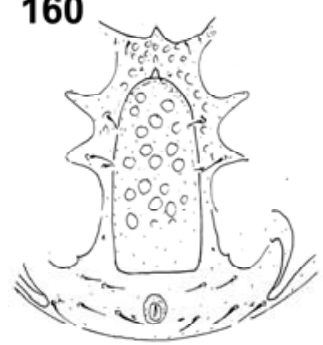

147-160. ábrák. Ausztrálázsiai és orientális Rotundabaloghia (Circobaloghia) fajok hasi nézete a legfontosabb karakterekkel.

Figures 147-160. Ventral aspect of the known Australasian and Oriental Rotundabaloghia (Circobaloghia) species. 
Rotundabaloghia (Circobaloghia) haradai HIRAMATSU, 1983 (151. ábra)

Rotundabaloghia haradai HIRAMATSU: 1983 pp. 128-130, Figs 25-33.

Rotundabaloghia haradai: HIRSCHMANN \& HIRAMATSU 1992 p. 10, HIRSCHMANN 1992d p. 96, WIŚNIEWSKI \& HIRSCHMANN 1993 p. 73, WIŚNIEWSKI 1993a p. 280, WIŚNIEWSKI 1993b p. 395, KONTSCHÁN 2010a p. 97.

Elterjedés: Indonézia, Borneó.

\section{Rotundabaloghia (Circobaloghia) levigata HIRAMATSU, 1983 (152. ábra)}

Rotundabaloghia levigata HIRAMATSU: 1983 pp. 130, Figs 34-43.

Rotundabaloghia levigata: HIRSCHMANN \& HIRAMATSU 1992 p. 10, HIRSCHMANN 1992d p. 97, WIŚNIEWSKI \& HIRSCHMANN 1993 p. 79, WIŚNIEWSKI 1993a p. 280, WIŚNIEWSKI 1993b p. 395, KONTSCHÁN 2010a p. 97.

Elterjedés: Indonézia, Borneó.

\section{Rotundabaloghia (Circobaloghia) tenera HIRAMATSU, 1983 (153. ábra)}

Rotundabaloghia tenera HIRAMATSU: 1983 pp. 130-132, Figs 44-53.

Rotundabaloghia tenera: HIRSCHMANN \& HIRAMATSU 1992 p. 10, HIRSCHMANN 1992d p. 97, WIŚNIEWSKI \& HIRSCHMANN 1993 p. 79, WIŚNIEWSKI 1993A p. 280, WIŚNIEWSKI 1993b p. 396, KONTSCHÁN 2010a p. 97.

Elterjedés: Indonézia, Borneó.

\section{Rotundabaloghia (Circobaloghia) polygonalis HIRSCHMANN, 1992 (154. ábra)}

Rotundabaloghia sp. B2. HIRAMATSU: 1983 pp. 130-132, Figs 44-53.

Rotundabaloghia polygonalis HIRSCHMANN: 1992 p. 11.

Rotundabaloghia polygonalis: HIRSCHMANN \& HIRAMATSU 1992 p. 10, HIRSCHMANN 1992d p. 97, WIŚNIEWSKI \& HIRSCHMANN 1993 p. 76, WIŚNIEWSKI 1993a p. 280, WIŚNIEWSKI 1993b p. 396, KONTSCHÁN 2010a p. 98.

Elterjedés: Indonézia, Borneó.

\section{Rotundabaloghia (Circobaloghia) reticulata HIRAMATSU, 1983 (155. ábra)}

Rotundabaloghia reticulata HIRAMATSU: 1983 pp. 122-123, Figs 1-13.

Rotundabaloghia reticulata: HIRSCHMANN \& HIRAMATSU 1992 p. 10, HIRSCHMANN 1992d p. 96, WIŚNIEWSKI \& HIRSCHMANN 1993 p. 70, WIŚNIEWSKI 1993a p. 280, WIŚNIEWSKI 1993 b p. 396, KONTSCHÁN 2010a p. 98.

Elterjedés: Indonézia, Borneó. 
Rotundabaloghia (Circobaloghia) rarosi HIRAMATSU \& HIRSCHMANN, 1992 (156. ábra)

Rotundabaloghia rarosi HIRAMATSU \& HIRSCHMANN: 1992 p. 10, Fig. p. 18.

Rotundabaloghia rarosi: HIRAMATSU \& HIRSCHMANN 1992 p. 17, HIRSCHMANN 1992d p. 96, WIŚNIEWSKI \& HIRSCHMANN 1993 p. 70, WIŚNIEWSKI 1993a p. 280, WIŚNIEWSKI 1993b p. 396, KONTSCHÁN 2010a p. 98.

Elterjedés: Fülöp-szigetek.

Rotundabaloghia (Circobaloghia) garciai Hiramatsu \& Hirschmann, 1992 (157. ábra)

Rotundabaloghia garciai HIRAMATSU \& HIRSCHMANN: 1992 pp. 21-22., Fig. p. 21.

Rotundabaloghia garciai: HIRAMATSU \& HIRSCHMANN 1992 p. 17, HIRSCHMANN 1992d p. 97, WIŚNIEWSKI \& HIRSCHMANN 1993 p. 73, WIŚNIEWSKI 1993a p. 280, WIŚNIEWSKI 1993b p. 395, KONTSCHÁN 2010a p. 98.

Elterjedés: Fülöp-szigetek.

\section{Rotundabaloghia (Circobaloghia) haradasimilis HIRAMATSU \& HiRSCHMANN, 1992} (158. ábra)

Rotundabaloghia haradasimilis HIRAMATSU \& HIRSCHMANN: 1992 p. 22, Figs p. 23.

Rotundabaloghia haradasimilis: HIRSCHMANN \& HIRAMATSU 1992 p. 10, HIRSCHMANN 1992d p. 97, WIŚNIEWSKI \& HIRSCHMANN 1993 p. 73, WIŚNIEWSKI 1993b p. 395, CORPUZ-RAROS \& DRUÉZO 2005 p. 195, KONTSCHÁN 2010a p. 99.

Elterjedés: Fülöp-szigetek.

\section{Rotundabaloghia (Circobaloghia) tobiasi KonTSCHÁn, 2014 (159. ábra)}

Rotundabaloghia (Circobaloghia) tobiasi KONTSCHÁN: 2014 pp. 39-42, Figs 12-20.

Elterjedés: Malajzia, Sabah.

\section{Rotundabaloghia (Circobaloghia) javaensis KONTSCHÁN \& KISS, 2015 (160. ábra)}

Rotundabaloghia (Circobaloghia) javaensis KONTSCHÁN \& KISS: 2015 pp. 521-524, Figs 25-32.

Elterjedés: Indonézia, Jáva.

Depressorotundiinae KoNTSCHÁN, 2010 alcsalád

Depressorotundiinae KONTSCHÁN, 2010a: 102.

Diagnózis: A ventrális oldalon egy vagy két nagy mélyedés található. A nőstény ivarlemezének alapja és a hím ivarnyílása a 4. láb csípői között látható.

Típus nem: Depressorotunda KonTSCHÁN, 2010.

Elterjedés: Amfipacifikus. 


\section{Didepressorotunda KonTSCHÁN, 2010 nem}

Didepressorotunda KonTSCHÁn, 2010a: 102.

Diagnózis: A nőstény ivarlemeze nyelv alakú, elülső szegélyén apró tüske alakú nyúlvánnyal. Peritréma kampó alakú. Két ventrális mélyedés van, egy pár adanális szőr látható.

Típus faj: Didepressorotunda auriculata (HIRSCHMANN, 1992).

Elterjedés: Borneó, Indonézia.

\section{Didepressorotunda auriculata (HIRSCHMANN, 1992)}

Rotundabaloghia sp. B3. HiRAMATsU: 1983 pp. 136-137, Figs 67-74.

Rotundabaloghia auriculata HIRSCHMANN: 1992 p. 11.

Rotundabaloghia auriculata: HIRSCHMANN \& HIRAMATSU 1992a p. 10, HIRSCHMANN 1992b p. 97, WIŚNIEWSKI \& HIRSCHMANN 1993 p. 72, WIŚNIEWSKI 1993a p. 280, WIŚNIEWSKI 1993 b p. 394.

Didepressorotunda auriculata: KONTSCHÁN 2010a p.102.

Elterjedés: Indonézia, Borneó.

\section{Depressorotunda KonTSCHÁN, 2010 nem}

Depressorotunda KonTSCHÁN, 2010b: 1462-1463.

Diagnózis: A ventrális lemezen egy nagy és mély üreg található, amely szegélyén három vagy négy pár szőr ül. A nőstény ivarlemeze nyelv vagy pajzs alakú, az alulsó szegélye a 4. láb csípői között helyezkedik el. A hím ivarlemeze kör alakú és a 3 és 4 . láb csípői között található. A peritréma kampó vagy R-alakú.

Típus faj: Depressorotunda malayana KONTSCHÁN, 2010.

Elterjedés: Délkelet-Ázsia és Dél-Amerika.

\section{Depressorotunda KonTSCHÁN, 2010 alnem}

Depressorotunda KonTSCHÁn, 2010a: 103.

Diagnózis: A ventrális lemezen egy nagy és mély üreg található, amely szegélyén három vagy négy pár szőr ül. A nőstény ivarlemeze nyelv vagy pajzs alakú, az alulsó szegélye a 4. láb csípői között helyezkedik el. A hím ivarlemeze kör alakú és a 3 és a 4. láb csípői között található. A peritréma kampó vagy R-alakú. Az adanális szőrök hiányoznak.

Típus faj: Depressorotunda (Depressorotunda) malayana KonTSCHÁn, 2010.

Elterjedés: Délkelet-Ázsia.

\section{Depressorotunda (Depressorotunda) malayana KonTSCHÁn, 2010 (161. ábra)}

Depressorotunda malayana KONTSCHÁN: 2010b pp. 1463-1465, Figs 1-2.

Depressorotunda malayana: KONTSCHÁN 2010a p.104.

Elterjedés: Malajzia. 

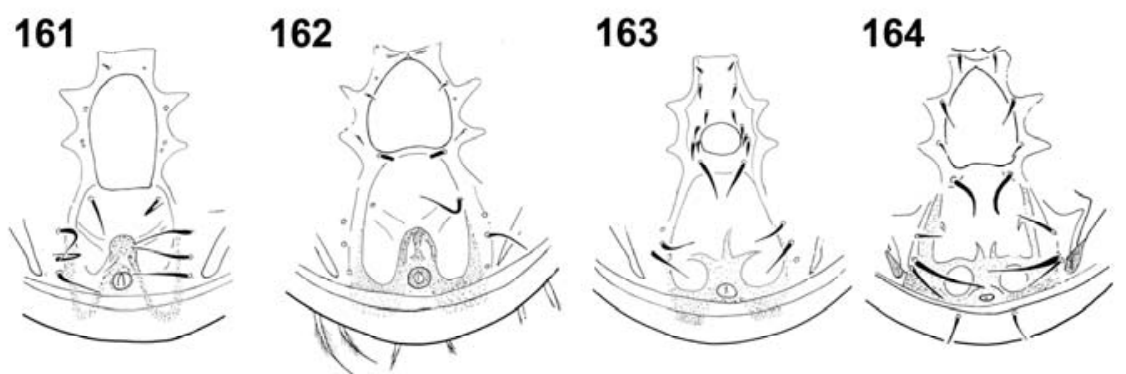

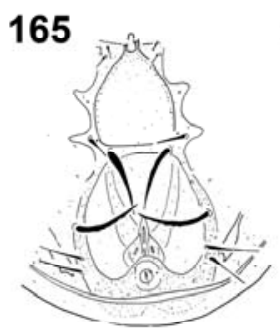

166

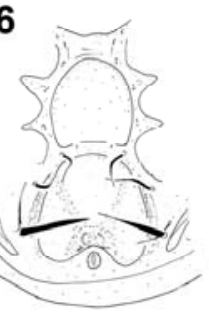

169

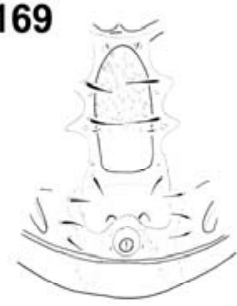

170

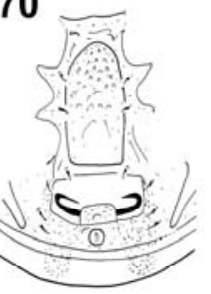

167

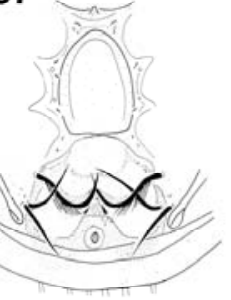

171

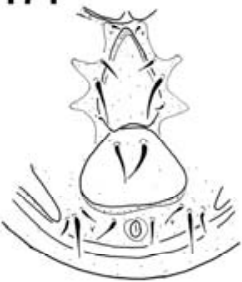

168

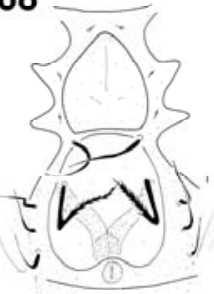

172

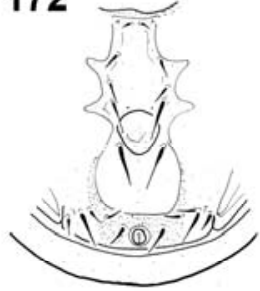

161-172. ábrák. Az Depressorotunda fajok hasi nézete a legfontosabb karakterekkel. Figures 161-172. Ventral aspect of the known Depressorotunda species.

Depressorotunda (Depressorotunda) seticaudata KonTSCHÁN, 2010 (162. ábra)

Depressorotunda seticaudata KONTSCHÁN: 2010b pp.1465-1468, Figs 4.

Depressorotunda seticaudata: KONTSCHÁN 2010a p.104.

Elterjedés: Malajzia.

\section{Depressorotunda (Depressorotunda) thailandica KonTSCHÁN, 2010 (163. ábra)}

Depressorotunda thailandica KonTSCHÁN: 2010b pp. 1468-1470, Figs 5

Depressorotunda thailandica: KONTSCHÁN 2010a p.104.

Elterjedés: Thaiföld. 
Depressorotunda (Depressorotunda) mirifica KonTSCHÁN, 2010 (164. ábra)

Depressorotunda mirifica KONTSCHÁN: 2010b pp. 1470-1471, Figs 6.

Depressorotunda mirifica: KONTSCHÁN 2010a p.104.

Elterjedés: Vietnam.

Depressorotunda (Depressorotunda) alveolata KONTSCHÁN \& STARÝ, 2011 (165. ábra)

Depressorotunda (Depressorotunda) alveolata KonTSCHÁN \& STARÝ: 2011 23-24, Figs 61-63.

Elterjedés: Vietnam.

Depressorotunda (Depressorotunda) batuensis KONTSCHÁN \& STARÝ, 2012 (166. ábra)

Depressorotunda (Depressorotunda) batuensis KONTSCHÁN \& STARÝ: 2012 p. 189, Figs 28-30.

Elterjedés: Malajzia.

Depressorotunda (Depressorotunda) serrata KonTSCHÁN, 2014 (167. ábra)

Depressorotunda (Depressorotunda) serrata KonTSCHÁN: 2014 pp. 42-45, Figs 21-31.

Elterjedés: Malajzia, Sabah.

Depressorotunda (Depressorotunda) robusta KONTSCHÁN \& KISS, 2015 (168. ábra)

Depressorotunda (Depressorotunda) robusta KonTSCHÁN \& KISs: 2015 p. 524, Figs 39-49.

Elterjedés: Indonézia, Szumátra.

Depressorotunda (Depressorotunda) hirca KonTSCHÁN \& KISS, 2015 (169. ábra)

Depressorotunda (Depressorotunda) hirca KonTSCHÁN \& KIss: 2015 pp. 524-528, Figs 50-55.

Elterjedés: Indonézia, Szumátra.

\section{Depressorotunda (Depressorotunda) taurina KonTSCHÁN, 2015 (170. ábra)}

Depressorotunda (Depressorotunda) taurina KonTsChÁn: 2015a pp. 50-51, Figs $21-$ 29.

Elterjedés: Hong Kong, Kína. 


\section{Amerorotunda KontsCHÁn, 2010 alnem}

Amerorotunda KonTSCHÁN, 2010a: 105.

Diagnózis: A ventrális lemezen egy nagy és mély üreg található, amely szegélyén három vagy négy pár szőr ül. A nőstény ivarlemeze nyelv vagy pajzs alakú, az alulsó szegélye a 4. láb csípői között helyezkedik el. A hím ivarlemeze kör alakú és a 3 és a 4. láb csípői között található. A peritréma kampó vagy R-alakú. Az adanális szőrök megfigyelhetőek.

Típus faj: Depressorotunda (Amerorotunda) ecuadorica KonTSCHÁn, 2010

Elterjedés: Ecuador.

\section{Depressorotunda (Amerorotunda) ecuadorica KonTSCHÁn, 2010 (171. ábra)}

Depressorotunda (Amerorotunda) ecuadorica KonTSCHÁN: 2010a pp.105-106, Fig. 190.

Elterjedés: Ecuador.

\section{Depressorotunda (Amerorotunda) splendida KonTSCHÁN, 2010 (172. ábra)}

Depressorotunda (Amerorotunda) splendida KONTSCHÁN: 2010a pp. 107-108, Fig. 191.

Elterjedés: Ecuador.

\section{Kulcs a családokhoz, alcsaládokhoz, nemekhez és az alnemekhez}

1, Egy vagy két mélyedés található a ventrális lemezen (Depressorotundiinae alcsalád) ......4

- Nincsen mélyedés a ventrális lemezen (Rotundabaloghiinae alcsalád).

2, A nőstény ivarlemeze háromszögletes vagy félkör alakú. Angulobaloghia nem

- A nőstény ivarlemeze nyelv vagy pajzs alakú (Rotundabaloghia nem). .3 Rotundabaloghia alnem

- Az összes dorzális szőr egyforma méretü és alakú. Circobaloghia alnem

4, Egyetlen ventrális mélyedés látható (Depressorotunda nem)..... 5

- Két ventrális üreg látható Didepressorotunda nem

5, Anális szőrök hiányoznak .Depressorotunda alnem

- Anális szőrök megfigyelhetőek Amerorotunda alnem 


\section{A Rotundabaloghiidae család fajainak biológiája és állatföldrajza}

Ha a nemek és alnemek elterjedését nézzük, igen feltűnő az Orientális régió és Ausztrálázsia faj- és taxongazdagsága. Az Angulobaloghia és a Didepressorotunda nemek, valamint Rotundabaloghia (Rotundabaloghia) és a Depressorotunda (Depressorotunda) alnemek kizárólag ebben a földrajzi régióban terjedtek el, ami egybevág azzal a hipotézissel, hogy ez a terület Földünk egyik legjelentősebb biodiverzitási gócpontja (MEYERS et al 2000). Bár jelenleg adataink nincsenek rá, feltételezhetjük, hogy innen terjedt szét a család, és az egyes taxonok, pl. a Rotundabaloghia (Circobaloghia) alnem innen kiindulva kolonizálta az összes trópusi területet. Nagyon érdekes az Angulobaloghia nem indiai előfordulása. Mivel a génusz sem Madagaszkáron, sem Afrikában nem fordul elő, ezért az előfordulása a gondvánai eredetű indiai szubkontinensen Délkelet-Ázsiából történő kolonizáció eredménye lehet. Továbbá az is valószínüsíthető, hogy az utolsó glaciális periódusban, amikor a tenger szintje a jelenleginél alacsonyabb volt, az Angulobaloghia nem tagjai az ázsiai kontinensről szárazföldi hidak segítségével kolonizálhatták a fülöp-szigeteki és az indonéz szigetvilágot, illetve Japánt. A mélyebb tengerrel elválasztott két régió (orientális és az új-guineai) két közeli tagja (Celebesz és Borneó) között valamilyen más transzporttal (pl. madarak lábán, átsodródó fák vagy kókuszdiók segítségével) jöhetett létre a kolonizáció. Feltételezhetően hasonlóan terjedtek szét a délkelet-ázsiai szigetvilágban a Rotundabaloghia (Rotundabaloghia) és a Depressorotunda (Depressorotunda) alnemek is. A Depressorotunda nem másik alnemének neotrópusi előfordulása nehezen magyarázható. Elképzelhető, hogy Afrikában is előfordulhatnak a nemnek tagjai, ami így egy gondwánai eredetet feltételezhet, de a taxon viszonylagos alulkutatottsága miatt erröl még nincsenek információink.

Az eddig felfedezett Rotundabaloghiidae családba tartozó fajok a trópusi esőerdők talajában, lehullott avarjában és az ott élő mohákban éltek. Az egyéb speciális korongatka élöhelyekröl (pl. hangyák, madarak, emlősök fészkeiből, ürülékből, illetve a leveleken és az ágakon kialakult talajból) nem sikerült még őket kimutatni. A trópusi mezőgazdasági területek korongatkáit átvizsgálva afrotrópusi és neotrópusi Pinus radiata ültetvényekböl is sikerült Rotundabaloghiidae fajokat kimutatnom (KONTSCHÁN 2015a, 2016). Tehát egyes trópusi agrárterületek megfelelő élőhelyek lehetnek a család fajainak.

\section{Irodalom}

Corpuz-Raros, L. A. \& DruÉzo, S. G. (2005): Preliminary list of soil mites (Acari) from the Samar Island Natural Park, Philippines with descriptions of a new species and a new record of Oribatida. Asia Life Sciences 14(2): 191-206.

HALlidAY, R.B. (2016): Catalogue of families and their type genera in the mite Suborder Uropodina (Acari: Mesostigmata). Zootaxa 4061(4):347-66. https://doi.org/10.11646/zootaxa.4061.4.2

Hiramatsu, N. (1977): Gangsystematik der Parasitiformes. Teil 239. Teilgang einer neuen Rotundabaloghia-Art aus Japan (Dinychini, Uropodinae). Acarologie. Schriftenreihe für Vergleichende Milbenkunde 23: 19-20. 
Hirschmann, W. (1972): Gangsystematik der Parasitiformes. Teil 127. Teilgänge, Stadien von 19 neuen Uroobovella-Arten (Dinychini, Uropodinae). Acarologie. Schriftenreihe für Vergleichende Milbenkunde 18: 110-119.

HiRschmanN, W. (1975a): Gangsystematik der Parasitiformes. Teil 201. Die Gattung Rotundabaloghia nov. gen. Hirschmann 1975 (Dinychini, Uropodinae). Acarologie. Schriftenreihe für Vergleichende Milbenkunde 21: 23-26.

HirschmanN, W. (1975b): Gangsystematik der Parasitiformes. Teil 202. Adult bestimmungstabelle von 20 Rotundabaloghia-Arten (Dinychini, Uropodinae). Acarologie. Schriftenreihe für Vergleichende Milbenkunde 21: 26-28.

HiRsChmanN, W. (1975c): Gangsystematik der Parasitiformes. Teil 203. Teilgänge, Stadien von 16 neuen Rotundabaloghia-Arten (Dinychini, Uropodinae). Acarologie. Schriftenreihe für Vergleichende Milbenkunde 21: 28-34.

HiRSCHMANN, W. (1979): Stadiensystematik der Parasitiformes Teil 1. Stadienfamilien und Stadiengattungen der Atrichopygidiina, erstellt im Vergleich zum Gangsystem Hirschmann, 1979. Acarologie. Schriftenreihe für Vergleichende Milbenkunde 26: 57-68.

HiRsCHMANN, W. (1981): Gangsystematik der Parasitiformes. Teil 416. Stadien von 2 neuen Uroobovella-Arten (Dinychini, Uropodinae). Acarologie. Schriftenreihe für Vergleichende Milbenkunde 28: 121-122.

Hirschmann, W. (1984): Gangsystematik der Parasitiformes. Teil 449. Gang, Teilgänge, Stadien von 6 neuen Rotundabaloghia-Arten aus Rwanda, Kolumbien und Kamerun. Acarologie. Schriftenreihe für Vergleichende Milbenkunde 31: 25-31.

Hirschmann, W. (1992a): Gangsystematik der Parasitiformes. Teil 534. 26 Rotundabaloghia-Arten aus Afrika (Ghana, Kamerun, Kongo, Rwanda, Tanzania) (Dinychini, Uropodinae). Acarologie. Schriftenreihe für Vergleichende Milbenkunde 39: 25-45.

Hirschmann, W. (1992b): Gangsystematik der Parasitiformes. Teil 536. 41 Rotundabaloghia-Arten aus Südamerika (Venezuela, Ekuador, Peru, Bolivien, Brasilien) und Mittelamerika (Guatemala) (Dinychini, Uropodinae). Acarologie. Schriftenreihe für Vergleichende Milbenkunde 39: 69-95.

HiRSCHMANN, W. (1992c): Gangsystematik der Parasitiformes. Teil 537. Adultengruppen, Verzeichnisse der 129 Rotundabalogia-Arten (Dinychini, Uropodinae). Acarologie. Schriftenreihe für Vergleichende Milbenkunde 39: 96-99.

HiRsChMANN, W. \& HirAmATsu, N. (1992): 34 Rotundabaloghia-Arten aus Asien (Japan, Neuguinea, Philippinen, Borneó) (Dinychini, Uropodinae). Acarologie, Schriftenreihe für Vergleichende Milbenkunde 39: 9-25.

Kontschán, J. (2004): Uropodina mites of East Africa (Acari: Mesostigmata) II. New Rotundabaloghia Hirschmann, 1975 species from Kenya. Folia Entomologica Hungarica 65: 511.

Kontschán, J. (2005): New Rotundabaloghia Hirschmann, 1975 species (Acari: Mesostigmata: Uropodina) from the Dominican Republic. Annales Historico-Naturales Musei Nationalis Hungarici 97: 241-249.

KontschÁn, J. (2006): Uropodina (Acari: Mesostigmata) species from Angola. Acta Zoologica Academiae Scientiarum Hungaricae 52: 1-20.

Kontschán, J. (2007a): A new Rotundabaloghia Hirschmann, 1975 species from Cuba (Acari: Mesostigmata: Uropodina). Acta Zoológica Mexicana (n.s) 23: 135-137.

KonTSCHÁN, J. (2007b): Uropodina mites (Acari: Mesostigmata) from Venezuela, with descriptions of four new species. Acta Zoologica Academiae Scientiarum Hungaricae 53(4): 335-346. 
Kontschán, J. (2007c): Two new Rotundabaloghia Hirschmann, 1975 species from Madagascar (Acari Mesostigmata: Uropodina). Annales Historico-Naturales Musei Nationalis Hungarici 99: 171-176.

Kontschán, J. (2008a): Four new species of Rotundabaloghia Hirschmann, 1975 from East Africa (Acari: Uropodidae). Zootaxa 1853: 18-30.

Kontschán, J. (2008b): Rotundabaloghia korsosi sp. nov. (Acari: Uropodina) from Taiwan. Collection and Research 21: 45-51.

KontschÁn, J. (2008c): New and rare Rotundabaloghia species (Acari: Uropodina) from the tropics. Opuscula Zoologica Budapest 38: 15-41.

Kontschán, J. (2009a): New Uropodina species (Acari: Mesostigmata) and records from Kenya Biologia, Bratislava 64(4): 737-741.

KontschÁN, J. (2009b) Uropodina mites (Acari) collected in Costa Rica, 1. Opuscula Zoologica Budapest 40(1): 23-33.

Kontschán, J. (2009c): Three new species of Rotundabaloghia Hirschmann, 1975 from Brazil (Acari: Uropodidae). Genus 20(2): 381-389.

KonTSCHÁN, J. (2009d): Rotundabaloghia browni spec. nov., a new uropodine mite from Ivory Coast. Spixiana 32(1): 35-38.

Kontschán, J. (2010a): Rotundabaloghiid mites of the world (Acari: Mesostigmata: Uropodina). AdLibrum Kiadó, Budapest, 116. pp.

Kontschán, J. (2010b): Depressorotunda gen. nov., a new remarkable Uropodina mite genus from South-East Asia with description of four new species (Acari: Mesostigmata). Journal of Natural History 44(23-24): 1461-1473. https://doi.org/10.1080/00222931003678784

KonTSCHÁN, J. (2010c): New and little known Uropodina species from Brazil (Acari: Mesostigmata). Acta Zoologica Academiae Scientiarum Hungaricae 56(4): 317-334.

KonTSCHÁN, J. (2014): Three new rotundabaloghid mites (Acari, Uropodina) from Sabah (Malaysia). Zookeys 447: 35-45. https://doi.org/10.3897/zookeys.447.8389

Kontschán, J. (2015a): Three new rotundabaloghid mites (Acari: Uropodina) from Hong Kong. Revue Suisse de Zoologie 122(1): 45-54

Kontschán, J. (2015b): Two new Uropodina species (Acari: Uropodidae) from a Pinus radiata plantation in Kenya. Acta Zoologica Academiae Scientiarum Hungaricae 61(1): 33-45. https://doi.org/10.17109/AZH.61.1.33.2015

KontsCHÁn, J. (2016): Uropodina mites (Acari: Mesostigmata) from agricultural areas of Ecuador. Opuscula Zoologica Budapest 47(1): 93-99. https://doi.org/10.18348/opzool.2016.1.93

KonTSCHÁN, J. \& KISS, B. (2015): Five new rotundabaloghiid mites (Acari: Uropodina) from SouthEast Asia. Zootaxa 4021(4): 515-528. https://doi.org/10.11646/zootaxa.4021.4.2

KONTSCHÁN, J. \& STARÝ, J. (2011): Uropodina mites from Vietnam (Acari: Mesostigmata). Zootaxa 2807: 1-28.

Kontschán, J. \& StARÝ, J. (2012): New Uropodina species and records from Malaysia (Acari: Mesostigmata). Acta Zoologica Academiae Scientiarum Hungaricae 58(2): 177-192.

KONTSCHÁN. J. \& STARÝ, J. (2014): New species of Uropodina from Madagascar (Acari: Mesostigmata). Zootaxa 3895: 547-569. https://doi.org/10.11646/zootaxa.3895.4.5

KREFT, H. \& JETZ, W. (2010): A framework for delineating biogeographical regions based on species distributions. Journal of Biogeography, https://doi.org/10.1111/j.1365-2699.2010.02375.x 
Meyers, N., Mittermeier, R.A., Mittermeier, C.G., Da Fonseca, G.A.B. \& Kent, J. (2000): Biodiversity hotspots for conservation priorities. Nature 403: 853-858. https://doi.org/10.1038/35002501

Wallace, A. R. (1876) The geographical distribution of animals. Harper \& Brothers, New York, 576 pp.

WiŚNIEWSKI, J. (1993a): Gangsystematik der Parasitiformes. Teil 549. Die Uropodiden der Erde nach Zoogeographischen Regionen und Subregionen geordnet (Mit Angabe der Lande). Acarologie. Schriftenreihe für Vergleichende Milbenkunde 40: 221-291.

WIŚNIEWSKI, J. (1993b): Alphabetisches verzeichnis der Uropodiden (Gattungen, Arten, Synonyma). Acarologie. Schriftenreihe für Vergleichende Milbenkunde 40: 371-429.

WiŚNIEWSKI, J. \& HiRschmanN, W. (1993): Gangsystematik der Parasitiformes. Teil 548. Katalog der Ganggattungen, Untergattungen, Gruppen und Arten der Uropodiden der Erde. Acarologie. Schriftenreihe für Vergleichende Milbenkunde 40: 1-220. 


\title{
New illustrated catalog of the species of the family Rotundabaloghiidae KonTSCHÁn, 2010 (Acari, Mesostigmata)
}

\section{JENŐ KONTSCHÁN}

Plant Protection Institute, Centre for Agricultural Research, Hungarian Academy of Sciences, P.O. Box 102, H-1525 Budapest, Hungary

E-mail: kontschan.jeno@agrar.mta.hu

ÁLLATTANI KÖZLEMÉNYEK (2016) 101(1-2): 79-131.

\begin{abstract}
The rotundabaloghid mites are one of most diverse family within the Uropodina suborder in the tropical regions. These species are easy recognise based on small and lentil-like body, the fusion of the marginal and dorsal shields, the position of genital shields of females and males and the reduction of the ventral setae. The first genus was described in 1975 and later more than 150 species were added to this taxon. After a revision, it is discussed currently as family (Rotundabaloghidae) with two subfamily (Rotundabaloghinae and Depressorotundinae), four genera (Angulobaloghia, Rotundabaloghia, Didepressorotunda and Depressorotunda) and two subgenera [Rotundabaloghia (Circobaloghia) and Depressorotunda (Amerorotunda)]. All bibliographic data of every known rotundabaloghid mites are listed with diagnoses and with a key for the family, subfamilies, genera and subgenera. Illustrations on the most important characters of the species are given.
\end{abstract}

Key words: Mites, taxonomy, faunistic, identification key, tropics. 